\title{
SELF-REGULATORY ORGANIZATIONS UNDER THE SHADOW OF GOVERNMENTAL OVERSIGHT: AN EXPERIMENTAL INVESTIGATION
}

\section{Silvester Van Koten Andreas Ortmann}

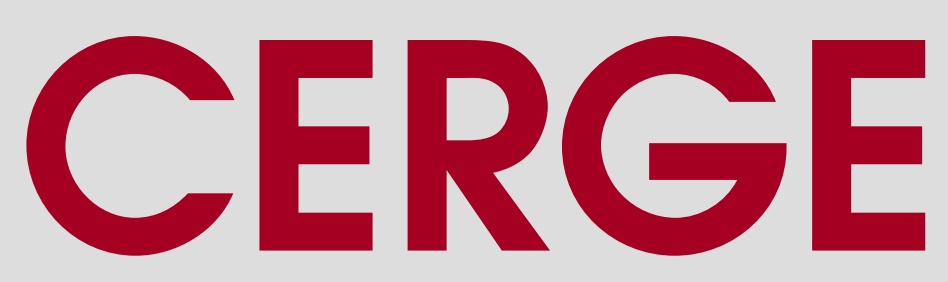




\section{Working Paper Series (ISSN 1211-3298)}

\section{Self-Regulatory Organizations Under the Shadow of Governmental Oversight: An Experimental Investigation}

Silvester Van Koten

Andreas Ortmann

CERGE-EI

Prague, November 2014 
ISBN 978-80-7343-324-6 (Univerzita Karlova. Centrum pro ekonomický výzkum a doktorské studium)

ISBN 978-80-7344-316-0 (Akademie věd České republiky. Národohospodářský ústav) 


\title{
Self-Regulatory Organizations Under the Shadow of Governmental Oversight: An Experimental Investigation*
}

\author{
SILVESTER VAN KOTEN $^{* *}$ and ANDREAS ORTMANN ${ }^{\dagger}$
}

\begin{abstract}
Self-regulatory organizations (SROs) can be found in education, healthcare, and other not-forprofit sectors as well as in the accounting, financial, and legal professions. DeMarzo et al. (2005) show theoretically that SROs can create monopoly market power for their affiliated agents, but that governmental oversight, even if less efficient than oversight by the SRO, can largely offset the market power. We provide an experimental test of this conjecture. For carefully rationalized parameterizations and implementation details, we find that the predictions of DeMarzo et al. (2005) are borne out.
\end{abstract}

\begin{abstract}
Samoregulační organizace (SROs) najdeme v oblasti vzdělání, zdravotní péče a dalších neziskových sektorech, stejně jako v účetnictví, finančních či právnických profesí. DeMarzo et al. (2005) teoreticky ukazují, že SROs mohou na trhu vytvářet monopol pro své členy, ale že státní dozor, i v př́padě menší produktivnosti než dozor z SRO, může výrazně snížit monopolní sílu členů SRO. Poskytujeme experimentální test této teorie. Pečlivým racionalizováním parametrializací a implementačních detailů potvrzujeme teorii DeMarzo et al. (2005).
\end{abstract}

Key words: Experimental Economics, Self-regulatory organizations, Governmental oversight

JEL classification: C90, L44, G18, G28

\footnotetext{
* Acknowledgements: We thank Chris Bidner, Jay Pil Choi, Hodaka Morita, as well as audience members at the ESA meetings 2011 in Luxembourg and 2012 in Cologne, the ANZ Workshop on Experimental Economics in Melbourne in 2011, and seminar participants at CERGE-EI and the University of Sydney, for very helpful comments. All errors remaining in this text are the responsibility of the authors. The research was developed with institutional support by RVO: 67985998 and Loyola de Palacio chair at the RSCAS of the European University Institute. Financial support from the Interní Grantová Agentura VŠE (IGS) grant IG505014 is gratefully acknowledged. Van Koten is grateful for the financial support in the form of the PRE Corporate Chair.

** The Department of Institutional Economics, University of Economics, Prague, Czech Republic; CERGE-EI, a joint workplace of Charles University and the Economics Institute of the Academy of Sciences of the Czech Republic, Politických vězňů 7, 11121 Prague, Czech Republic

Corresponding author. Fax: +420 224005 333. Tel: +420 776125053. Email: silvester.vankoten@ cerge-ei.cz and silvester.vankoten@vse.cz.

${ }^{\dagger}$ Australian School of Business, UNSW, Sydney, NSW 2052, Australia
} 


\section{Introduction}

Self-regulatory organizations (SROs) can be found in education, healthcare, and (other) not-for-profit sectors, as well as the accounting, financial, and legal professions (DeMarzo et al. 2005; Studdert et al. 2004; Sidel 2005; Hilary and Lennox 2005; Maute 2008; Ortmann and Mysliveček 2010; Ortmann and Svitkova 2010); they can even be found in the nuclear power industry. Examples include financial industry regulatory authorities (Stefanadis 2003), the so-called Donors Forums in not-for-profit sectors in Central and Eastern Europe (Ortmann and Svitkova 2010), and the Institute of Nuclear Power Operations in the nuclear power industry (Rees 1997; DeMarzo et al. 2005). The healthcare and education sectors are often regulated by systems of accreditation that are similar to self-regulatory entities.

Gehrig and Jost (1995) showed that self-regulation by an SRO results in lower consumer surplus than oversight by a government. However, Gehrig and Jost (1995) reach this conclusion assuming - somewhat unrealistically - that oversight by a government is costless. DeMarzo et al. (2005) analyze the outcomes when the oversight by the government is costly and more expensive than oversight by SRO as the government has less access to information. DeMarzo et al. (2005) assume that an SRO or government do not necessarily investigate each complaint, but that they set ex-ante a probability (the "investigation probability") with which they investigate each complaint. DeMarzo et al. (2005) show that, in general, a profit-maximizing investigation probability is less than 100\%. DeMarzo et al. (2005) further show that without governmental oversight, SROs can create monopoly market power for their affiliated agents by setting the investigation probability very low. The authors, however, also argue that the shadow of governmental oversight, even if less efficient than oversight by the SRO, can largely offset market power. In other words, the mere outside threat of government oversight might overcome the incentive-incompatibility problem that some have argued afflicts self-regulatory bodies (e.g., Shaked and Sutton 1981; Nunez 2001, 2007; Ortmann and Mysliveček 2010). 
We experimentally test the predictions of DeMarzo et al. (2005). ${ }^{1}$ Using carefully rationalized parameterizations and implementation details, we find that the predictions of DeMarzo et al.'s (2005) model are borne out.

In the following section we briefly sketch the model in DeMarzo et al. (2005). In section 3 we explain how we have translated their theoretical model into an experimentally testable format. In section 4 we rationalize our choice of particular parameterizations and other design and implementation choices. In section 5 we report our results. In section 6 we conclude with a discussion of our results.

\section{The Model}

In the DeMarzo et al. (2005) model, an agent affiliated with an SRO provides a service for a client, such as making an investment. The outcome of the investment can be high or low, and is not directly observable for the client, but can be verified by the SRO at some cost. ${ }^{2}$ An opportunistic agent may have an incentive to deceive a client by reporting a low outcome when it is in fact high, and then keep the payoff difference himself. The agent thus needs to be incentivized to be honest. The agent can be incentivized with a "whip" or with a "carrot". When an agent is found to have deceived a client, he could be given a financial punishment (the whip), and when the agent reports a high outcome, he could be given a bonus in the form of a success fee (the carrot). For a client, the cheapest method to incentivize the agent is a "whip": to apply a punishment if the agent has been deceptive. This strategy is, however, only applicable if the SRO detects the misreporting, which requires monitoring and incurs a cost.

DeMarzo et al. (2005) show that an SRO that maximizes the aggregate profits of its agents - left to its own devices-will set the investigation probability i $p_{S R O}^{*}$ inefficiently low, leaving punishment ineffective as an incentive for the agent to act honestly. As a result the client is forced to use "carrots": offering the agent a large proportion of the outcome as a success fee. When clients are homogeneous in their

\footnotetext{
${ }^{1}$ See Eckel and Lutz (2003) for an introduction to the role of economics experiments in research on regulation.

${ }^{2}$ Notice that this is a difference with Gehrig and Jost (1995) who assume a client learns the true outcome after having used the service.
} 
outside options, the SRO will set $i p_{\text {SRO }}^{*}$ so low that the fee will extract all the surplus of the investment. Clients thus will have an expected profit equal to their outside option. Homogeneity of clients is, of course, not a particularly likely feature of real-world markets. When clients are heterogeneous in their outside options, a low investigation probability may dissuade clients with high outside options from entering. The SRO sets an investigation probability that maximizes the product of the expected fee and number of clients that will participate. From a welfare point of view, the resulting outcome is undesirable.

DeMarzo et al. (2005) show that effective governmental oversight may largely offset the market power the SRO has given to the agents. The government (GOV) itself can start an investigation and assign penalties when fraud is detected. Governmental oversight is effective if the investigation probability the government (GOV) sets when there is no oversight by an SRO is larger than the investigation probability the SRO sets when there is no oversight by GOV (DeMarzo et al. 2005, p. 14). Importantly, DeMarzo et al. (2005) assume that GOV and SRO move sequentially, with the government moving last. This argument seems rationalizable in that it is GOV that ultimately has the power to punish. GOV thus observes the investigation probability of SRO and subsequently chooses an investigation probability to maximize its profits (the aggregated consumer surplus of all clients). The choice of GOV can thus be characterized by a reaction function that has as its one argument the choice of the SRO: $i p_{G O V}\left[i p_{S R O}\right]$. The strategies of the SRO can be characterized by a likewise function $i p_{S R O}\left[i p_{G O V}\right]$. Using our definition of effective governmental oversight from above, the reaction function of GOV must thus fulfill $i p_{G O V}[0]>i p_{S R O}[0]$ (GOV prefers a higher investigation probability than $\mathrm{SRO}$ ), where $i p_{G O V}[0]$ is the investigation probability GOV sets when there is no oversight by SRO and $i p_{S R O}[0]$ is investigation probability the SRO sets when there is no oversight by GOV. DeMarzo et al. (2005) show that GOV will choose an investigation probability which is strictly positive for every level 
of SRO investigation probability that is lower than $i p_{G O V}[0]$ and equal to zero when the SRO sets an investigation probability equal to $i p_{G O V}[0] .^{3}$

The additional investigation by GOV lowers the agents' market power and also the success fee necessary to induce the agent to behave honestly. GOV has, however, higher investigation costs than SRO: $c_{G O V}>c_{S R O}$. As clients bear the investigation costs, the high costs of GOV dissuade clients with high outside options from entering, thus lowering the profits for both clients and agents. It is therefore in the interest of SRO to minimize the amount of investigation conducted by GOV. SRO can effectively preempt GOV by choosing $i p_{S R O}=i p_{G O V}[0]$, the investigation probability GOV would have chosen if GOV were the sole investigator, as GOV then chooses zero. This pre-emptive investigation probability ensures that the investigation is solely conducted by SRO and the resulting reduction in investigation costs dissuades fewer clients with high outside options from participating. This increased participation of clients increases the profits of both GOV and SRO.

\section{Experimental Implementation of the Theoretical Model}

We test the model of DeMarzo et al. (2005) experimentally. Such a test requires a number of decisions pertaining to design and implementation of the theoretical model. We assume that once SRO and GOV have announced their investigation probabilities, clients and agents make the Nash-equilibrium choices as derived in DeMarzo et al. (2005). Our test is thus focused on the behavior of SRO and GOV, which we consider the key protagonists of the story. As in DeMarzo et al. (2005), GOV has no incentives to duplicate an investigation already done by SRO. The total investigation probability is then equal to the GOV investigation probability plus the SRO investigation probability: $i p_{\text {Total }}=i p_{\text {SRO }}+i p_{G O V}$ (see footnote 17 of DeMarzo et al. 2005 for details). As players move sequentially, it would be irrational for GOV to choose $i p_{G O V}$ such that $i p_{S R O}+i p_{G O V}>1$, and we thus exclude such a move.

\footnotetext{
${ }^{3}$ Formally, this implies for the reaction functions that $i p_{\text {GOV }}\left[i p_{S R O}\right]>0$ for $i p_{S R O}[0]<i p_{G O V}[0]$ and $i p_{G O V}\left[i p_{S R O}\right]=0$ for $i p_{S R O}=i p_{G O V}[0]$.
} 
Investigations are costly and thus, once the investigation probabilities are known, the expected costs of investigation can be calculated. These costs are paid up front by clients as a transaction fee $t_{S R O}+t_{G O V}$. The fine $x$ levied on an agent found to have deceived a client is set at the maximum. Table 1 gives the timeline of actions for the case of heterogeneous agents.

Table 1 Timeline of actions for case of heterogeneous agents

\begin{tabular}{|l|l|}
\hline \multirow{2}{*}{1} & Stage \\
\cline { 2 - 3 } $\begin{array}{l}\text { Stage } \\
2\end{array}$ & $\begin{array}{l}\text { B) After observing } i p_{S R O}, \text { GOV chooses an investigation policy } i p_{G O V} \text {. } \\
\text { costs } t_{S R O}+t_{G O V}, \text { clients calculate the lowest success fee that induces the agent to act } \\
\text { honestly. The clients' expected profit with such a contract is equal to } a \text {. The } \\
\text { proportion of clients with outside options larger than } a, 1-F[a] \text {, will not deal with } \\
\text { the clients and take their outside options. The proportion of clients with outside } \\
\text { options smaller than } a, F[a], \text { will offer the contract to the agents. They pay the } \\
\text { transaction fees } t_{S R O}+t_{G O V} \cdot\end{array}$ \\
\hline $\begin{array}{l}\text { Stage } \\
3\end{array}$ & $\begin{array}{l}\text { Agents that report a low outcome are investigated with probability } i p_{S R O}+i p_{G O V} . \text { If } \\
\text { SRO investigates the agent, SRO pays the investigation cost } c_{S R O} \text { and, if the agent is } \\
\text { found to have made a dishonest report, the agent pays the penalty } x \text {. If GOV } \\
\text { investigates the agent, GOV pays the investigation cost } c_{G O V}>c_{S R O} \text { and the agent } \\
\text { pays the penalty } x .\end{array}$ \\
\hline
\end{tabular}

\section{Parameterization}

In this section we present our parameterizations (section 4.1.) and explain how we derived them from the model. We also present two alternative experimental treatments that we used as robustness tests (sections 4.3 and 4.4)

\subsection{Baseline and Alternative Parameterization}

A basic problem of experimental tests of this kind is the appropriate choice of parameterization; one would ideally like to calibrate the experiment to reasonably likely real-world scenarios. This has proven to be a very difficult problem especially for micro-economics experiments (e.g., see List 2006, for a rare successful calibration in 
this literature). If outright calibration is not possible, the researcher alternatively might want to systematically explore the universe of possible calibrations by casting an appropriate grid over it. Unfortunately, such a strategy is prohibitively expensive. This leaves as a third option the exploration of "plausible" sets of parameterizations where for key variables high and low values are chosen. It is this strategy that we use here. One can think of it as a very coarse grid search.

Another important experimental translation problem is that an SRO is - as the name suggests - an organization that is unlikely to have social preferences, as experimental participants might have. We will discuss this issue in our discussion and conclusion section below.

We explored three key variables: the success probability (LOW or HIGH), SRO investigation cost (LOW or HIGH) and GOV investigation cost (LOW, HIGH, or VERY HIGH). Our initial prior was that the cost differential-the difference between SRO and GOV investigation costs-would be of particular importance. As a robustness test for the effect of the cost differential, we included Very High investigation cost of GOV (55). ${ }^{4}$ Combined with the Low investigation cost of the SRO (10), this was meant to allow us to study the effect of a very large cost differential (GOV investigation costs are 5.5 times larger than those of SRO).

As in DeMarzo et al. (2005), we assumed clients are risk-neutral and agents are riskaverse. For the experimental design and implementation below, we assume that agents have a constant relative risk aversion utility function $u[x]=m \cdot x^{1-R A} / R A$, with a riskaversion set equal to $R A=0.5$, which is a typical degree of risk-aversion (Holt and Laury 2002). To lower the likelihood of social preferences affecting the experimental results, we choose, by setting the utility scaling factor $m$ equal to 10 , a constant relative risk aversion utility function that results in SRO payoffs being about the same magnitude as GOV payoffs in equilibrium. As the multiplication by $m>0$ is a monotonic transformation of the utility function, preferences are invariant for different positive values of $m$.

Table 2 gives the baseline parameterization and the three key variables.

\footnotetext{
${ }^{4}$ We chose the very high value for the cost, 55, as the midpoint of the distribution of the outside options of the clients.
} 
Table 2 Parameterizations (Success probability: (LOW/HIGH), cost difference: (LOW/HIGH/VERY HIGH))

\begin{tabular}{|ll|}
\hline Agent $(\mathrm{A})$ & \\
Client $(\mathrm{Cl})$ & Linear $(u[x]=x)$ \\
Utility function Clients & $u[x]=m \cdot x^{1-R A} / R A$ \\
Utility function Agents & $=10$ \\
Utility scaling factor $m$ & $=0.5$ \\
Risk Aversion Agents (RA) & $=20$ \\
Low investment outcome $(L)$ & $=200$ \\
High investment outcome $(H)$ & $=$ LOW (25\%) or HIGH (50\%) \\
Success Probability (SP) & UD over $[5,105]$ \\
Outside Option $(O O)$ & $=$ LOW (10) or HIGH (20) \\
Investigation Cost of SRO (ICsro) & $=$ LOW (20), HIGH (40), or VERY \\
Investigation Cost of GOV (ICg) & HIGH (55) \\
\end{tabular}

Note: The three key variables are in bold.

Given the structure of the game and assuming the optimal responses of agents and clients, as in DeMarzo et al. (2005), we created from the set-up in Table 2 the 8 parameterizations shown in Table 3. ${ }^{5}$ The payoff matrixes reflect subjects in the roles of SRO and GOV choosing selected monitoring probabilities. We present the payoffs to the subjects to capture the common knowledge assumption of DeMarzo et al. (2005). ${ }^{6}$

\footnotetext{
${ }^{5}$ Option "None" is equal to an SRO investigation probability of zero. Option "Low" is equal to the investigation probability that the SRO will set when left to its own devices, $i p_{S R O}^{*}$. Option "High" is equal to the investigation probability that GOV will set if SRO sets an investigation probability of zero, $i p_{G O V}[0]$, where $i p_{G O V}[0]>i p_{S R O}^{*}$. The investigation probabilities "Low" and "High" are thus slightly different for the different cost differentials and success probabilities. "Low" varies between $30 \%$ and $37 \%$ and "High" between $54 \%$ and $94 \%$.

${ }^{6}$ One could argue that by giving our subjects (enacting SRO and GOV) the payoff matrices, we have transformed the interaction and simply test whether subjects can "solve" somewhat complicated matrix games. We beg to differ. As mentioned, we have rationalized our payoffs carefully and believe that the payoffs capture the players' conceptualization of the interaction in the same way as other interactions are captured in payoff matrices. That is not to say that it would not be interesting to give subjects a description of the available options only, i.e., without explicit payoff options.
} 
Table 3 Overview of parameterizations

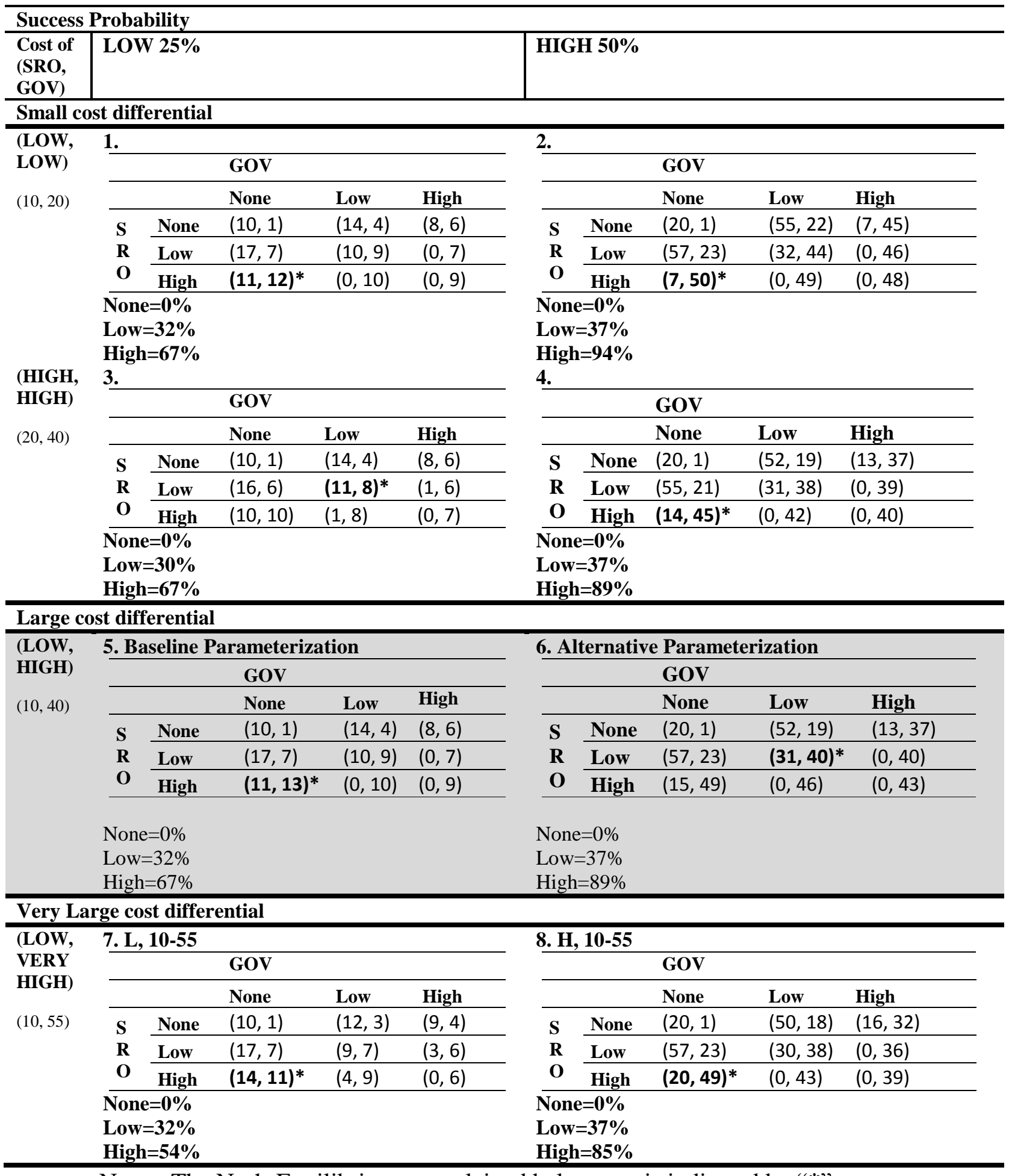

Notes: The Nash-Equilibrium —explained below_— is indicated by “*”. 
To repeat, DeMarzo et al. (2005) assume that government and the SRO move sequentially, with the government moving last. We do the same, even though above we have shown the payoffs in normal-form format.

As evidenced by the two sets of four cost differentials (one for LOW success probability in the left column, one for HIGH success probability in the right column), the investigation costs of GOV and SRO do not have very large effects. ${ }^{7}$ In contrast, the success probability induces considerable variability and increases the payoff contrast between the preferred outcomes. An increase in the success probability, for a given investigation probability, increases the gain from deceptive behavior, and thus, to keep agents incentivized to be honest, the success fee has to increase. Also, the (expected) cost of investigation goes down. As a result, the profit of the SRO increases. A secondorder effect is that SRO will set a slightly higher investigation probability, which will allow clients to pay slightly lower success fees; this increases the number of clients, further increasing the profit of SRO. The effect of an increase in success probability on the profit of GOV is also positive: the profitability of the project increases and thus the profit of GOV as well. The effect of an increase is the largest for SRO (GOV) for low (high) investigation probabilities, as agents then extract a large (small) share of the surplus of the investment.

For example, the increase in the success probability between the $5^{\text {th }}$ and $6^{\text {th }}$ parameterizations in Table 3 (which are labeled for reasons to be explained below Baseline Parameterization and Alternative Parameterization) increases the net profit for GOV the most for outcomes with a high investigation probability of the SRO. Specifically, the outcome $(\mathrm{SRO}, \mathrm{GOV})=($ High, None) sees a payoff increase from 13 to 49 for GOV, while the outcome $(\mathrm{SRO}, \mathrm{GOV})=($ None, None $)$ sees no increase at all, as in the latter case all surplus is extracted by agents. Analogously, the payoffs for SRO increase most for outcomes with a low investigation probability. Specifically, the outcome $(\mathrm{SRO}, \mathrm{GOV})=($ Low, None $)$ sees an increase from 17 to 57 for the SRO, while the outcome $(\mathrm{SRO}, \mathrm{GOV})=($ High, High $)$ sees no increase at all. The increase in the success probability thus increases the payoff contrast between the preferred outcomes.

\footnotetext{
${ }^{7}$ Note that the payoffs of the four matrices in the left column do not change much from row to row. Likewise, the payoffs of the four matrices in the right column do not change much from row to row. In contrast, there are considerable payoff changes for each row going from one column to the other.
} 
For our experimental treatments we focus on the parameterization with the lesser payoff contrast: the $5^{\text {th }}$ parameterization, referred to as "Baseline". We also use the $6^{\text {th }}$ parameterization (referred to as "Alternative") for a robustness test.

Note that the equilibrium in the Alternative parameterization in Table 3 has a different subgame perfect Nash-equilibrium, $(\mathrm{SRO}, \mathrm{GOV})=($ Low, Low $)$, than the one theory predicts, $(\mathrm{SRO}, \mathrm{GOV})=(\mathrm{High}, \mathrm{None})$. This is the result of the relatively flat payoff function for GOV and our implementation where players can only choose amongst three options (None, Low, High). At (Low, Low) the SRO has a payoff of 31 , and the GOV of 40 . If, as assumed in the theory, players could choose investigation probabilities from a continuum ranging from $0 \%$ to $100 \%$, GOV would not choose Low $(37 \%)$ or High $(89 \%)$, but $52 \%$ and its profit would be 42 . SRO would then have a profit of 13 , which is considerably lower than 31 and lower than the 15 that SRO would earn if it chose High (after which GOV would choose None). That discontinuous representations of continuous (relatively flat) payoffs may result in additional or different equilibria is a common problem in designing experiments (Holt, 1985; Huck, Müller \& Normann, 2001; Hinloopen, Müller \& Normann, 2012). One strategy is to slightly manipulate the pay-off table by adding or subtracting a small number from the payoffs so as to guarantee that the experimental representation has the same Nash equilibrium as the theoretical, continuous setup (Huck, Müller \& Normann, 2001, p. 753; Hinloopen, Müller \& Normann, 2012, p.9). In our case, even the smallest integer, "1", is large relative to the payoffs for GOV, and we thus decided not to manipulate the pay-off table.

\subsection{The Overall Design}

Parameterization 5, as discussed in the previous sections, is our main (Baseline) treatment. This parameterization is referred to in the box labelled "Baseline" in the summary of treatments in Figure 1. We also added robustness tests. As a first robustness test ("Alternative parameterization"), we added a treatment that uses parameterization 6 ("Alternative") in Table 3. As a second robustness test ("Complex"), we added a treatment with a higher degree of complexity, and as a third robustness test ("Extensive form"), we added a treatment with payoffs in the extensive game form rather than in the 
normal game form that we used in the other treatments. (To repeat, DeMarzo et al. assume that government and the SRO move sequentially, with the government moving last. We do the same even though above we have shown the payoffs in normal-form format.)

Normal form

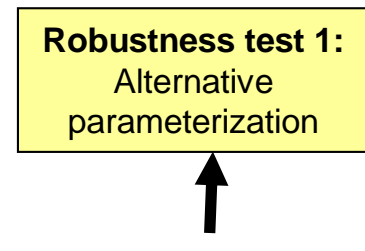

Baseline

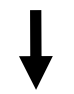

Robustness test 2: Complex
Extensive form

Robustness test 3:

Extensive form

Fig. 1 Summary of the treatments

We explain robustness tests 2 and 3 in sections 4.3 and 4.4. We can think of many other robustness tests-see the Conclusion and Discussion sections below-but our budget was limited and hence we had to make choices. These were the ones that struck us as the most insightful.

\subsection{Robustness Test 2: Normal-Form Representation In a Complex Format}

As a second robustness test, we increased the choice resolution from $3 \times 3$ to $6 \times 6$. Participants thus could choose from a set enlarged to 6 choices: \{None, Very Low, Low, Medium, High, Very High ${ }^{8}{ }^{8}$ For an example, see Figure 2. This complex

\footnotetext{
${ }^{8}$ Option "None" is equal to an investigation probability of zero. The investigation probability is then increased by $16.67 \%$ for each of the successive options. Thus, the option "Very Low" is equal to an investigation probability of $16.67 \%$, the option "Low" to one of $33.33 \%$, the option "Medium" to one of $50 \%$, and so on.
} 
representation has the same order of play and parameterization as the baseline treatment.

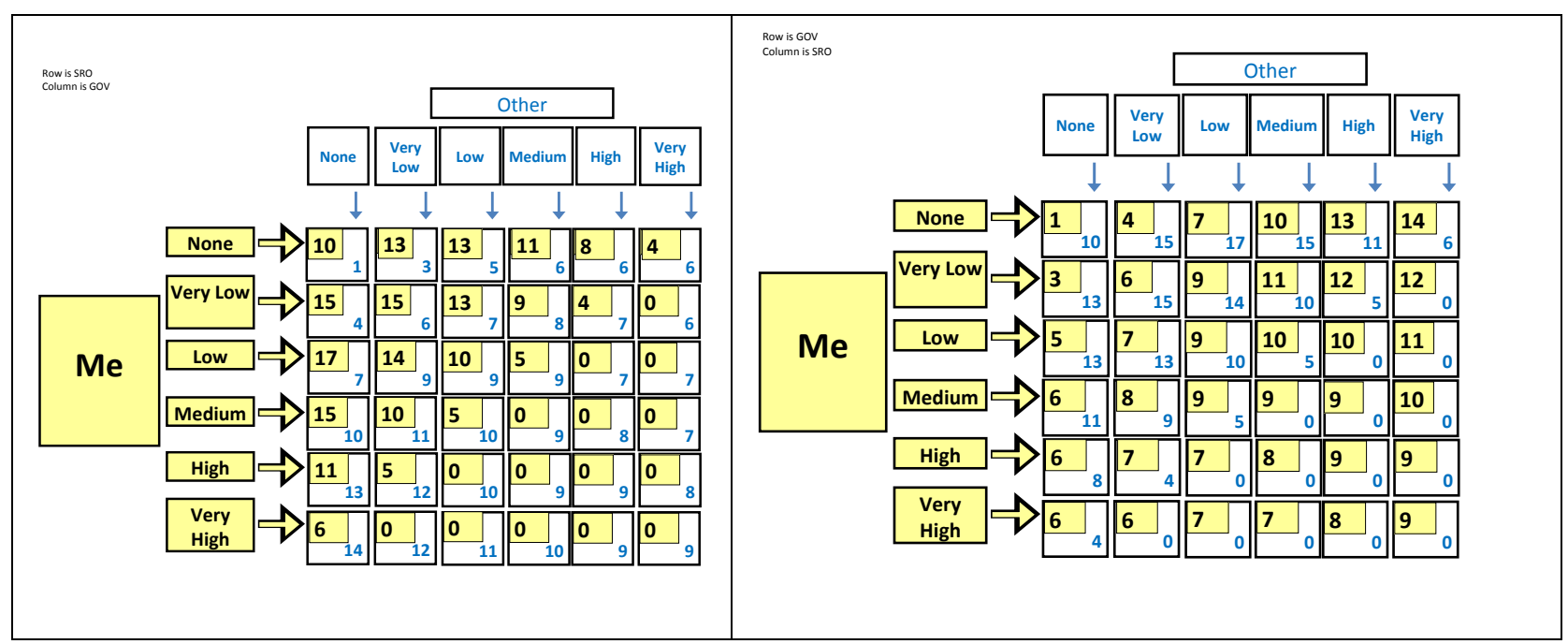

Fig. 2 Presenting the normal-form game to participants in a complex format

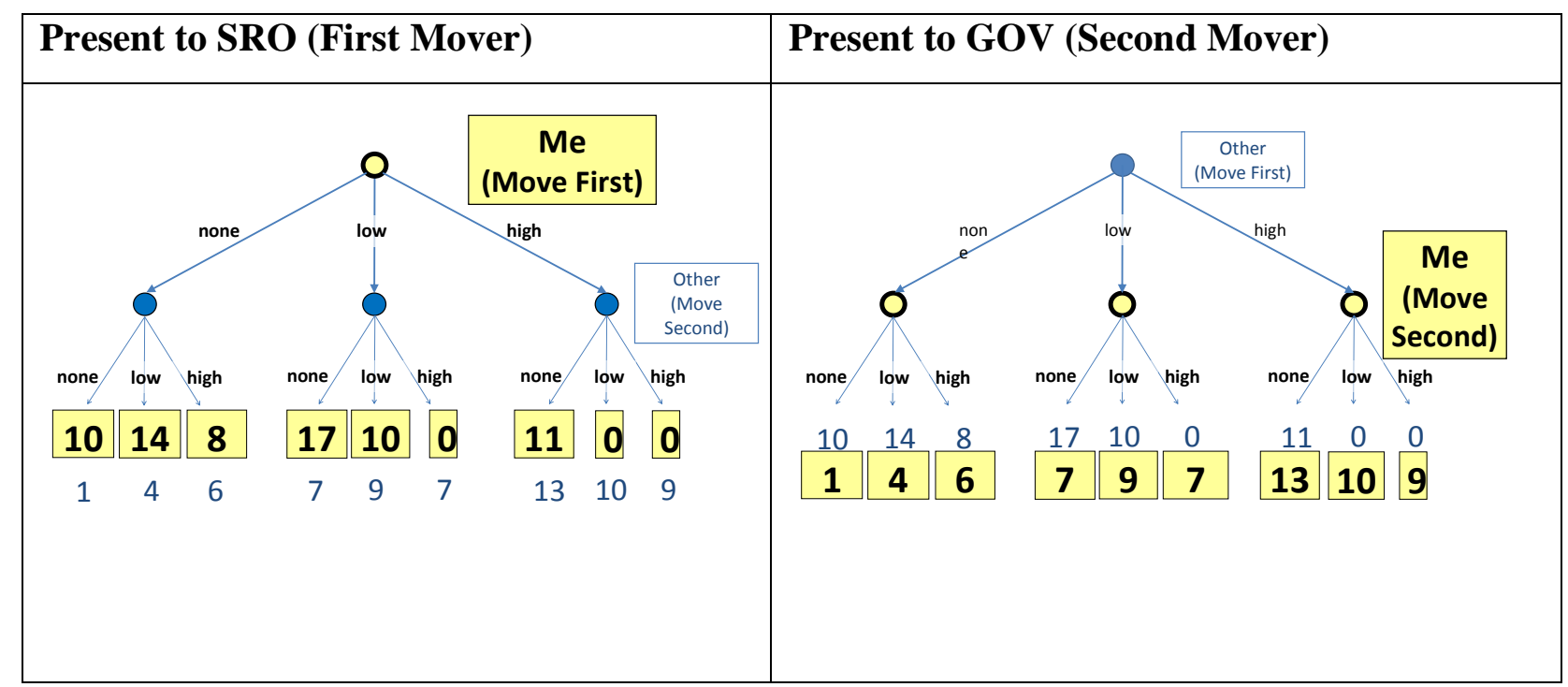

Fig. 3 Presenting the extensive-form game to participants

\subsection{Robustness Test 3: Extensive-Form Representation}

As a third robustness test, we presented the payoffs in the extensive game form, as this mode of presentation may be more congruent with the decision process in a sequential game than the normal-form presentation. The normal-form presentation might make it 
harder for participants to understand the structure of the sequential decision process. For an example, see Figure 3.

Table 4 Subgame-perfect Nash equilibria

\begin{tabular}{ll}
\hline & $\begin{array}{l}\text { Nash equilibrium } \\
\text { (SRO, GOV) }\end{array}$ \\
\hline Baseline treatment & (High, None) \\
\hline & \\
Robustness tests & \\
\hline $\begin{array}{l}\text { 1. Alternative } \\
\text { parameterization } \\
\text { (normal form) }\end{array}$ & (Low, Low) \\
\hline $\begin{array}{l}\text { 2. Baseline case } \\
\text { complex } \\
\text { (normal form ) }\end{array}$ & (High, None); \\
\hline $\begin{array}{l}\text { 3. Baseline case } \\
\text { (extensive form) }\end{array}$ & (High, None) \\
\hline
\end{tabular}

Table 5 Sessions, participants, and independent observations

\begin{tabular}{|c|c|}
\hline Baseline treatment & $\begin{array}{l}2 \text { sessions } \\
48 \text { participants } \\
8 \text { independent observations }\end{array}$ \\
\hline \multicolumn{2}{|l|}{ Robustness tests } \\
\hline $\begin{array}{l}\text { 1. Alternative parameterization } \\
\text { (normal form) }\end{array}$ & $\begin{array}{l}2 \text { sessions } \\
48 \text { participants } \\
8 \text { independent observations }\end{array}$ \\
\hline $\begin{array}{l}\text { 2. Baseline case complex } \\
\text { (normal form ) }\end{array}$ & $\begin{array}{l}2 \text { sessions } \\
48 \text { participants } \\
8 \text { independent observations }\end{array}$ \\
\hline 3. Baseline case (extensive form) & $\begin{array}{l}1 \text { session } \\
24 \text { participants } \\
4 \text { independent observations }\end{array}$ \\
\hline
\end{tabular}

4.5 Nash Equilibria For All Treatments and Experimental Implementation Details

Table 4 shows the subgame-perfect Nash equilibria for our Baseline treatment and the robustness tests. Due to the rounding of numbers, the Nash equilibria were not identical in some cases of the robustness test. In the first robustness test (Alternative 
Parameterization), the Nash equilibrium is (Low, Low). In the second robustness test, using the complex representation, rounding created other Nash equilibria in addition to the theoretical one: (Low, Very Low). ${ }^{9}$ We count these responses as Nash equilibrium choices in our tests below.

Table 5 gives an overview of our sessions. We ran a total of 7 sessions in December 2011 in the "LEE" experimental lab of the University of Economics in Prague. ${ }^{10}$ In each session we had 24 participants make decisions, as SRO or GOV, over 10 rounds. Following well-documented experimental practice, participants in each session were divided into 4 groups of 6 to increase the number of truly independent data points. In each group, 3 participants were randomly assigned the role of GOV and 3 the role of SRO. Roles were fixed throughout the session. In each round, participants were randomly matched with a participant playing the other role within their group. Each session thus resulted in $4(24 \div 6)$ independent observations. We ran a total of 7 sessions involving 168 participants, generating 28 independent data points. Participants in the role of SRO made the first choice and their choices were communicated to participants in the role of GOV with which they were matched. Then participants in the role of GOV made their choices. We used neutral language in the instructions (reprinted at the end of this manuscript), and all treatments were implemented using the direct-response method. Participants earned on average CKZ $360(\approx € 14, \approx \$ 19$, more than four times the gross hourly average wage in the Czech Republic in 2011) in a session of 50 minutes (including the reading of the instructions).

\footnotetext{
${ }^{9}$ In the complex representation, there is a subgame-perfect Nash equilibrium, (SRO, GOV) $=($ Low, Very Low $)$ in addition to the one predicted by theory, $(\mathrm{SRO}, \mathrm{GOV})=($ High, None). The extra Nash equilibrium is the result of rounding and, as in the case of the Alternative parameterization, the relatively flat payoff function for GOV. At (Low, Very Low) the SRO has a payoff of 14, and the GOV of 9 (8.5). If numbers are given with one decimal precision, the option Very Low would be dominated for GOV by option Low, which results in payoff $9(9.0)$. At (Low, Low) the payoff for SRO would be 10, which is lower than the 11 it could secure itself by choosing High.

${ }^{10}$ See www.vse-lee.cz. In addition, we ran 6 sessions where players made their choices simultaneously rather than sequentially. The results of these sessions do not provide evidence related to the theoretical model of DeMarzo et al. (2005) which has SRO and GOV move sequentially, and we therefore do not report them here. A detailed account can be found in Van Koten (2014).
} 


\section{Results}

In this section we show the proportion of choices by the participants in the experiments that are part of a subgame-perfect Nash equilibrium. We interpret the outcome of a high proportion of choices (or at least a convergence to that outcome) as experimental corroboration of DeMarzo et al.'s (2005) theoretical model.

5.1 Proportion of Nash equilibrium choices

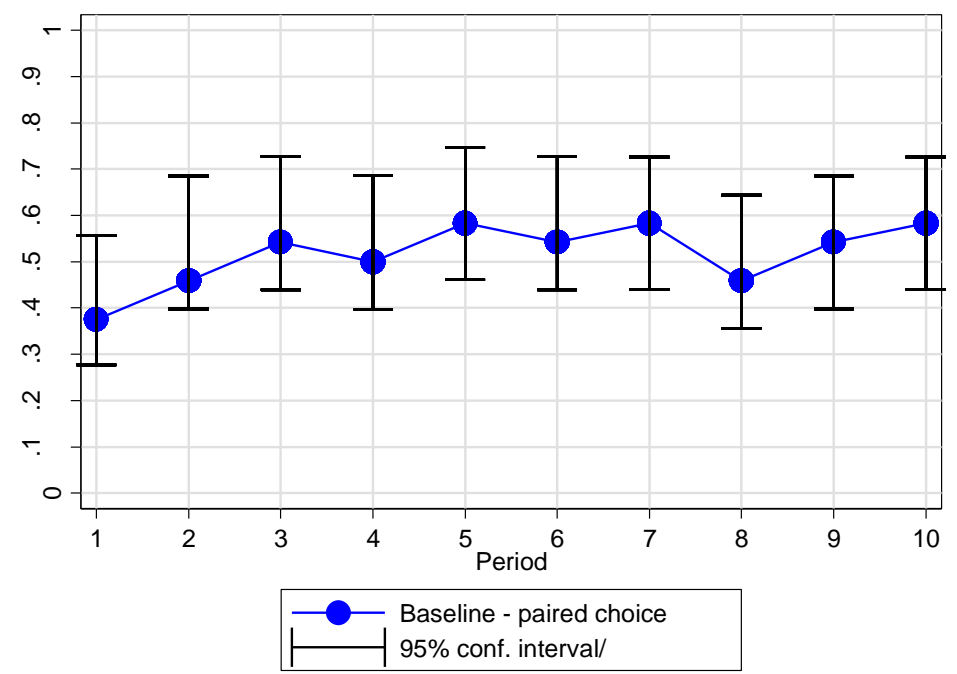

Fig. 4 Proportion of joint Nash equilibrium choices.

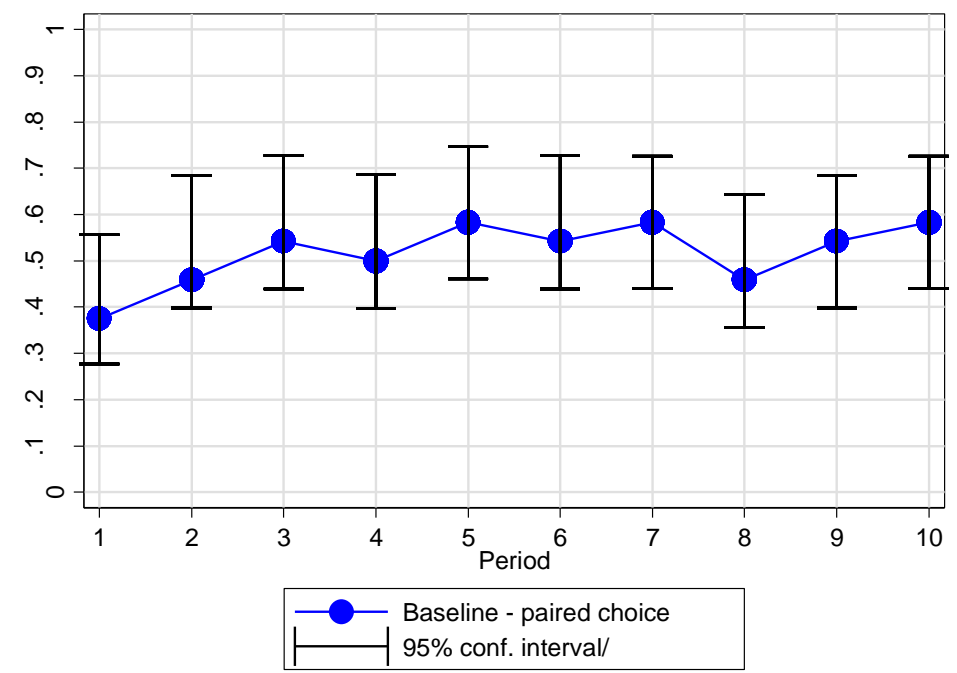


Fig. 4 shows the proportion of paired choices that are congruent with a Nash equilibrium. Initially, choices are far from a Nash equilibrium: typically in less than half the cases do the pairs make a Nash equilibrium choice. We see, however, a learning effect. In the last few rounds, paired choices are in all treatments in the range of 50\%$60 \%$. Note that pure chance play would result in success percentages of $11 \%$ for paired choices. However, learning is, less pronounced than we expected, reflecting the fact that subjects find it difficult to find sequential Nash equilibria. The subjects in the role of the first-mover (SRO) often make a choice different from the one implied by the subgame-perfect Nash equilibrium. ${ }^{11}$ The subjects in the role of second-mover (GOV) make highly rational choices (see Appendix). When SRO thus makes a first move that is a Nash equilibrium choice, in most cases the GOV makes a second move that is a Nash equilibrium as well and visa versa.

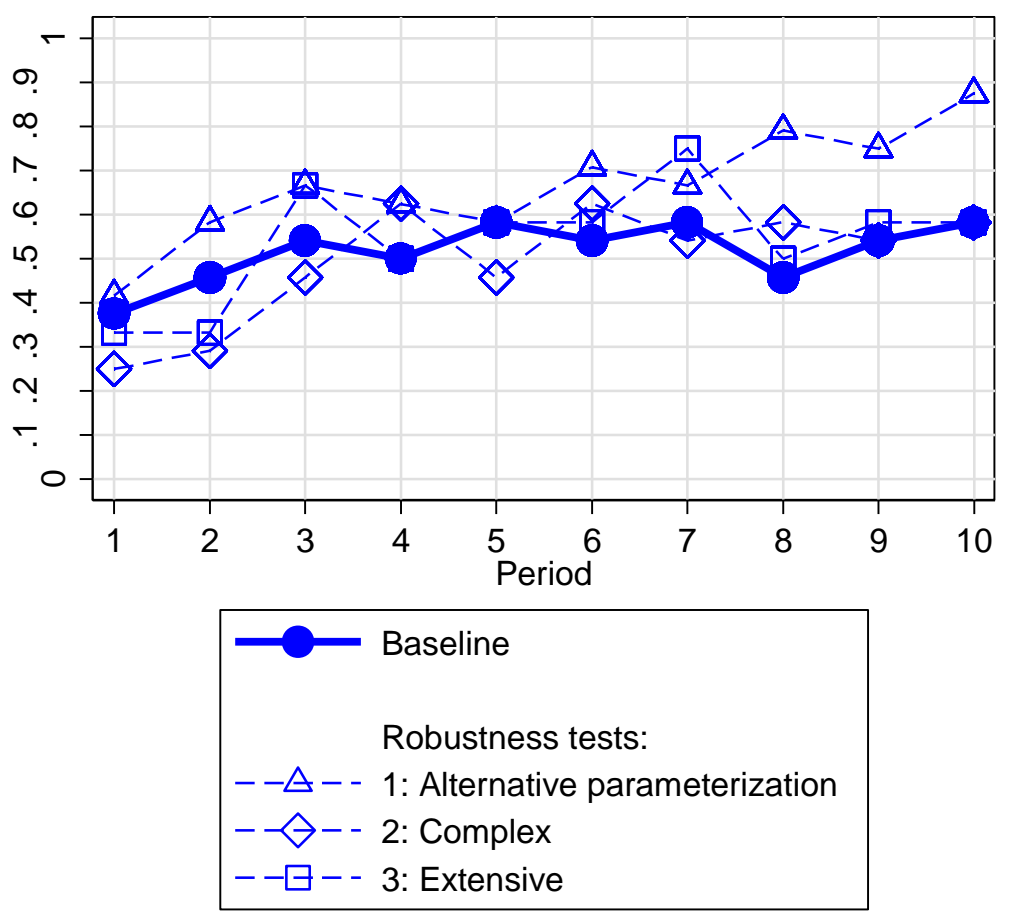

Fig. 5 Proportion of joint Nash equilibrium choices.

\footnotetext{
${ }^{11}$ Our finding of a rather high proportion of dominated choices may be surprising, but is in line with earlier studies. For example, see Rydval, Ortmann, and Ostatnicky (2009), who report $45 \%$ of dominated choices (where random choice predicts $56 \%$ of dominated choices) in simple symmetric, dominancesolvable guessing games
} 
While somewhat alike, the percentage of equilibrium choices in the Alternative Parameterization treatments ("Alternative") is higher initially and converges faster to full equilibrium play than the corresponding percentage in the Baseline. This is likely the result of the stronger contrast in payoffs for SRO and GOV in the Alternative parameterization. Recall that the Alternative parameterization has a stronger contrast because it has a higher success probability than the baseline (50\% versus $25 \%$ success probability).

Figure 5 shows the experimental results of our robustness tests (recall that we use an Alternative parameterization, a more complex format -6 by 6 instead of 3 by 3 - and an extensive form representation) together with the baseline treatment. The choices for the baseline treatment are indicated by a thick line with large round markers. The choices for the treatments of the robustness tests, Alternative parameterization, Complex representation and Extensive representation are indicated by thin lines with triangles, diamonds, and squares, respectively. The choices for the Complex treatment are very much in line with the three treatments that were presented in the simple format and very close to the average of these three. We conclude that our conclusions are robust to a different parameterization, a considerable increase in complexity (from 3 to 6 choices for each participant), and the use of an extensive-form representation.

\section{Discussion and Conclusion}

We have experimentally tested the interesting DeMarzo et al. (2005) model, in which the authors argue that the mere threat of punishment (government intervention) might lead to second-best self-regulation. This topic is of importance since many industries have been trying to rely on self-regulation, which has been theoretically argued to be incentive-incompatible (Shaked and Sutton 1981; Nunez 2001 2007; Mysliveček and Ortmann 2010; Ortmann and Svitkova 2010) and has indeed an empirically questionable track record (e.g., Kleiner 2006). In the light of a lack of empirical evidence of the efficacy of the threat of government intervention, we conducted an experimental test of the propositions in DeMarzo et al. (2005) and find 
that in specific parameterizations and implementation details, the predictions of their model are borne out.

As always in laboratory tests, a number of extensions and robustness tests suggest themselves. While we have carefully rationalized the appropriate parameterizations, there is room for further parametric exploration. We do not believe, however, that further exploration would lead to substantially different results for rationalizable parameterizations. As mentioned, an important experimental translation problem is that an SRO is an organization that is unlikely to be afflicted with social preferences, as experimental participants might. An obvious robustness test (as a considerable and growing literature has documented) would therefore be to let teams interact (e.g., Charness and Sutter 2012; Cooper and Kagel 2005). In light of the evidence that has emerged (suggesting that team interaction leads to more play in accordance with standard game theoretic predictions), we doubt that the essence of our results can be questioned on those grounds. Other obvious experimental treatments are those concerning standard experimental manipulations such as financial stakes or the question of the framing of instructions. Again, we do not believe that this would change our experimental results significantly (e.g., Rydval and Ortmann 2004). 


\section{APPENDIX A: Rational individual choices in the sequential game}

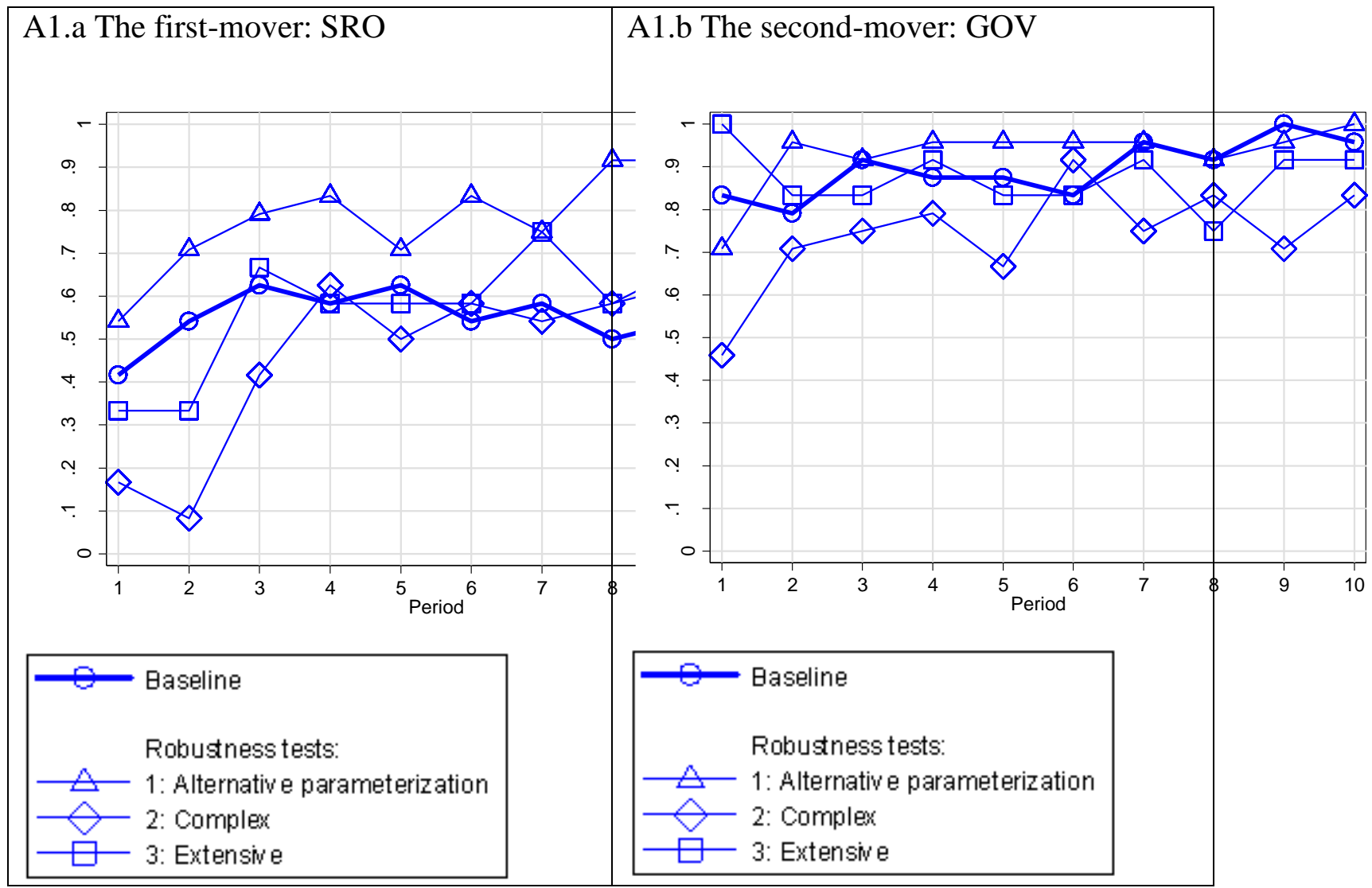

Fig. A1 Proportion of individual rational choices

In the sequential game SRO is the first-mover and GOV the second-mover. GOV thus makes its choice knowing the choice of SRO. This allows us to look if GOV makes profit-maximizing choices, knowing the choice of the choice of the first-mover SRO. Figure 5 shows the proportion of individual choices that are rational in the game. As before, the treatments for Baseline and Alternative parameterizations and Extensive representation are indicated by the round, square, and x-shaped markers, respectively. The choice of the first-mover, SRO, is regarded as rational if it is the Nash equilibrium choice. The choice of the second-mover, GOV, is regarded as rational if it is the best reply to the choice of the participant in the role of SRO he is paired with. The rational reply for GOV is thus only a Nash equilibrium choice if the paired SRO also made a Nash equilibrium choice. 
Figure A1.b shows that GOV makes highly rational choices. Already in the first few rounds, the proportion of rational choices is mostly above $80 \%$. In the last two rounds, the proportion of rational choices is above $90 \%$ in all treatments. While this may not be surprising ex-post, earlier studies, such as Rydval et al. (2009) show that very high proportions of subjects may choose dominated choices in simple guessing games. The participants in the role of SRO seem to struggle more to make rational choices. Figure 5.a shows that in the first rounds, the percentage of rational choices ranges between $30 \%-60 \%$ and in the last rounds between 50\%-90\%, indicating learning, most notably in the Alternative Parameterization (again, due to the larger pay-off contrast between SRO and GOV in this parameterization). Participants in the role of SRO have a more difficult task to make a rational choice, as they must deduce their best choices through backwards induction, assuming a rational response by GOV. It is thus to be expected that the process of convergence for participants in the role of the first-mover SRO is slower. It is reassuring that we see convergence for the choices of SRO and that the rational choices of GOV provide the correct incentive to SRO to learn the rational responses.

\section{Appendix B: Consolidated instructions}

Codes used to indicate the treatment:

Base $\quad-$ Baseline parameterization treatment of $3 \times 3$

Alt $\quad-$ Alternative parameterization treatment of $3 \times 3$

6x6 - A $6 \times 6$ payoff matrix

EXT - Extensive game representation.

A code indicating the start of a text referring to a specific treatment or set of treatments always starts with "[" and follows with the codes indicating the specific treatment(s). A code indicating the end of a text referring to a specific treatment or set of treatments always ends with the codes indicating the specific treatment(s) and finishes with "]".

\section{INSTRUCTIONS}

Welcome to the experiment!

\section{General rules}

Please turn off your mobile phones now. 
If you have a question, raise your hand and the experimenter will come to your desk to answer it.

You are not allowed to communicate with other participants during the experiment. If you violate this rule, you will be asked to leave the experiment and will not be paid (not even your show-up fee).

\section{Introductory remarks}

You are about to participate in an economics experiment. The instructions are simple. If you follow them carefully, you can earn a substantial amount of money. Your earnings will be paid to you in cash at the end of the experiment.

The currency in this experiment is called "Experimental Currency Units", or "ECU"s. At the end of the experiment, we will exchange ECUs for Czech Crowns as indicated below. Your specific earnings will depend on your choices and the choices of the participants you will be paired with.

Your exchange rate will be:

[Base

2 Czech Crowns for an ECU.

Base]

[Alt, 3x3, SRO

1.5 Czech Crown for an ECU.

Alt, 3x3, SRO]

[Alt, 3x3, GOV

0.5 Czech Crown for an ECU.

Alt, 3x3, GOV]

This experiment should take at most 60 minutes. There are 10 paid rounds in this experiment.

You are encouraged to write on these instructions and to highlight what you deem particularly relevant information.

\section{[Please go to the next page now.]}

\section{Group assignment}


You will always be a member of a group consisting of you and ONE other person in this room. Group membership is anonymous; you will not know who is in a group with you and the other person in your group will not know that you are in his or her group. Group membership is assigned anew in each round, in a random way.

You will be asked to make a series of interactive decisions in this experiment, i.e. your earnings in each round will depend both on your decision and that of the person that you are paired with for that round.

In each group one participant will be of Type 1 and the other one will be of Type 2 .

The Type 1 participant will make a decision first ("move first"). The choice of the Type 1 participant is then communicated to the Type 2 participant . The Type 2 participant will make a decision subsequently ("move second").

The roles of Type 1 and Type 2 are randomly assigned at the beginning of the experiment and remain the same throughout the experiment. Once the experiment starts, you will see whether you are Type 1 or Type 2 on your screen in the upper left corner. Below it you can also see the round. For an example, see Figure 6.

Figure 6

You are Type 1

Round 1 of 10

The participant assigned to you is

of Type 2

\section{[Please turn over]}

\section{Decision Screen}

In each round you will be presented with a Decision Screen where you will make a choice by clicking on one of the

$[3 \times 3$

three buttons labeled NONE, LOW, or HIGH.

$3 \times 3]$

$[6 \times 6$

six buttons labeled using NONE, VERY LOW, LOW, MEDIUM, HIGH, and VERY HIGH.

6x6]

See the example in Figure 7. 
Figure 7

$[3 \times 3$

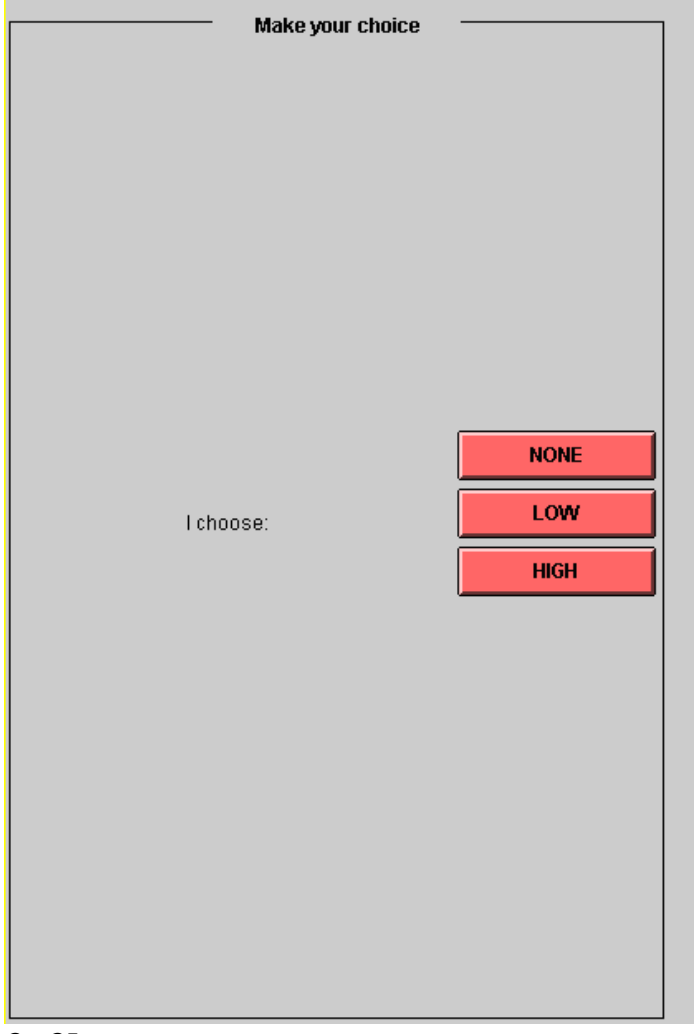

$3 \times 3]$

[6x6

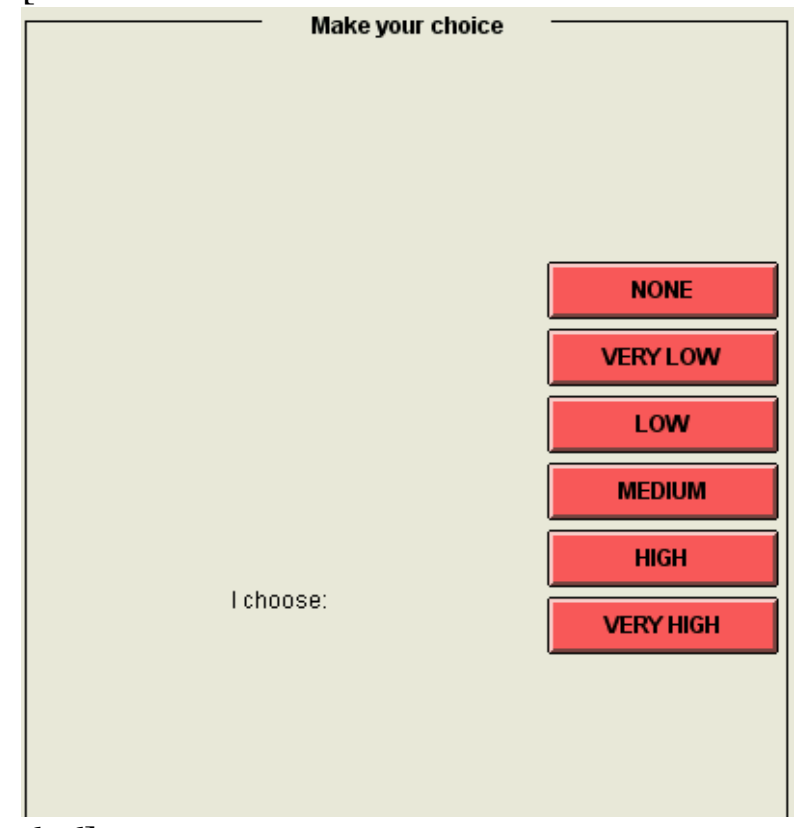

6x6] 
The example in Figure 7 shows how a Type 1 participant, who will move first, will make a choice. In Figure 8 is shown how a Type 2 participant, who will move second, will make a choice. As you can see in Figure 8, a Type 2 participant sees the choice that the Type 1 participant assigned to him or her for that round has made.

Figure 8

$[3 \times 3$

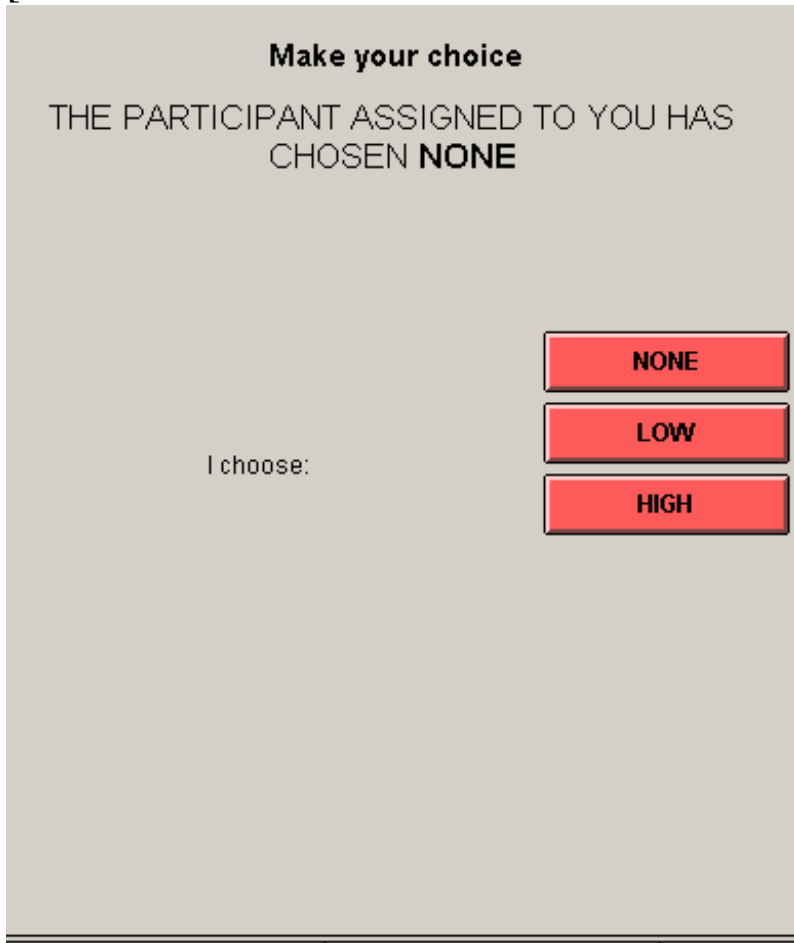

$3 \times 3]$

$[6 \times 6$

Make your choice

THE PARTICIPANT ASSIGNED TO YOU HAS CHOSEN NONE

NONE

VERY LOW

LOW

MEDIUM

HIGH

I choose:

VERY HIGH 
You can see your possible earnings and the possible earnings of the participant assigned to you for that round in the Earnings Table on the paper with the title "YOUR EARNINGS TABLE" which you find on your desk.

Your payoffs are in bolded black numbers on yellow background in the upper left corners of each cell of the Earnings Table. The payoffs of the participant assigned to you for that round are in blue numbers on a white background in the lower right corner of each square of the Earnings Table. To repeat, your earnings in each round will depend both on your choice and that of the person that is assigned to you for that round.

\section{EXAMPLE BOX}

In this EXAMPLE BOX we will explain how your choices and the choices of the participant that is assigned to you determine your earnings.

The Example Earnings Table in this EXAMPLE BOX is NOT the earnings table used in the experiment. In the experiment a different Earnings Table will be used: the one on your table with the title "YOUR EARNINGS TABLE".

Example Earnings Table 


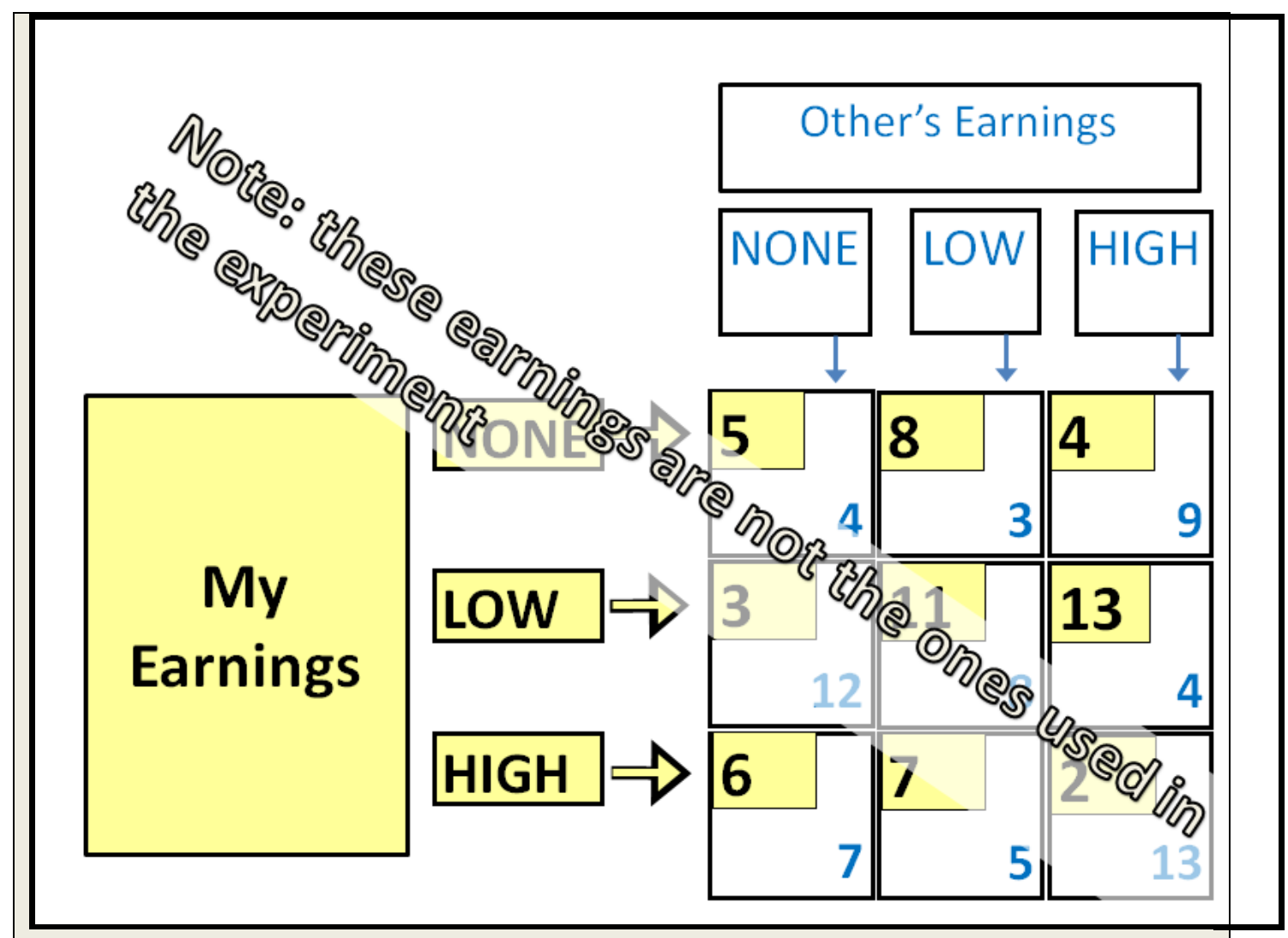

If the Example Earnings Table would be the relevant Earnings Table, then if the participant assigned to you chose NONE, your earnings will be 5 if you choose NONE, 3 if you choose LOW, and 6 if you choose HIGH. If the participant assigned to you chose LOW, then your earnings will be 8 if you choose NONE, 11 if you choose LOW, and 7 if you choose HIGH.

The earnings of the participant that is assigned to you are determined in a similar manner, with their earnings shown in the lower right corner of each square of the Example Earnings Table.

To make your choice you have one minute; if you have not made a choice during that time, the computer will assign you the choice of NONE. This is the standard procedure for all decisions in this experiment. You can see the time you have left to make a choice in the upper right corner of the screen ("Remaining time"), see Figure 9 for an example. 
Figure 9

Remaining time [sec]: $\quad 57$

To repeat, Type 1 will make a decision first ("move first"). The choice of Type 1 is then communicated to Type 2 . Type 2 will then make a decision ("move second").

After all participants have made their decisions, or if one minute has expired, the computer will calculate your earnings.

\section{Results Screen}

You will next see a Results Screen. The Results Screen will show your choice and the choice of the participant that is assigned to you for that round. The Results Screen will also show your and the other participants' earnings.

\section{EXAMPLE BOX}

In the example in Figure 3 you and the other participant chose NONE. In the example in Figure 3 your earnings are thus 5 and that of the other participant are 4 (to repeat: in the experiment a different Earnings Table will be used: the one on your desk with the title "YOUR EARNINGS TABLE"). 


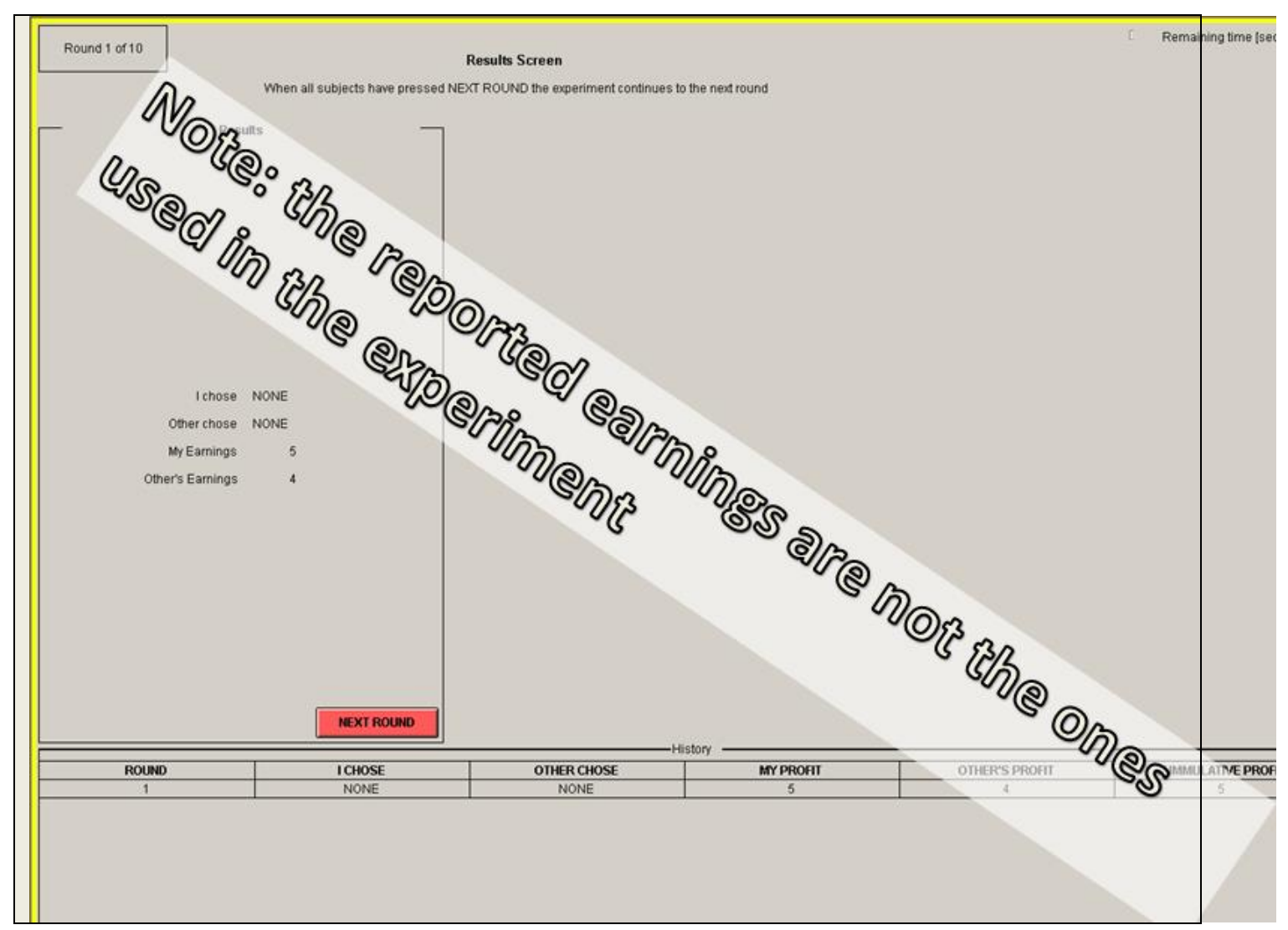

You have one minute to inspect the outcomes. (This is the standard time you have for inspecting results). When you need less time to inspect the outcomes, then click the NEXT ROUND button. Once all participants have clicked the NEXT ROUND button, the experiment continues with the next round. Note that the Results Screen will be visible until all participants have clicked on the NEXT ROUND button.

Do you have any questions at this point? 
[Base, 3x3, SRO

YOUR EARNINGS TABLE

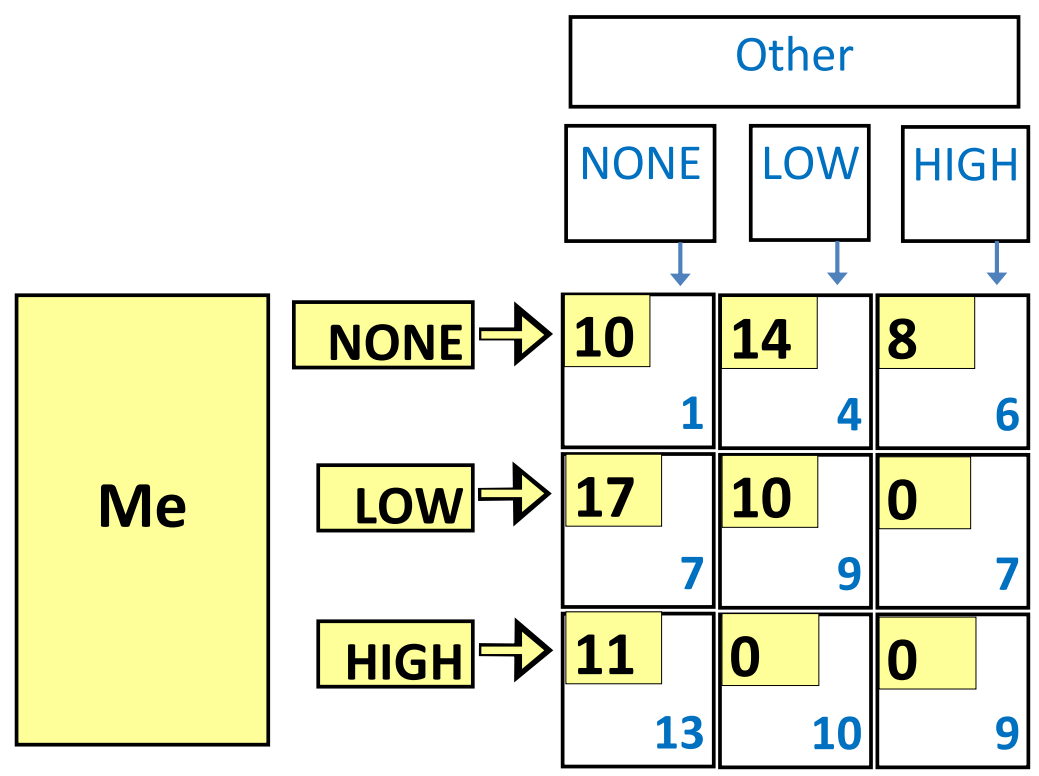

Base, 3x3, SRO]

[Base, 3x3, GOV

YOUR EARNINGS TABLE

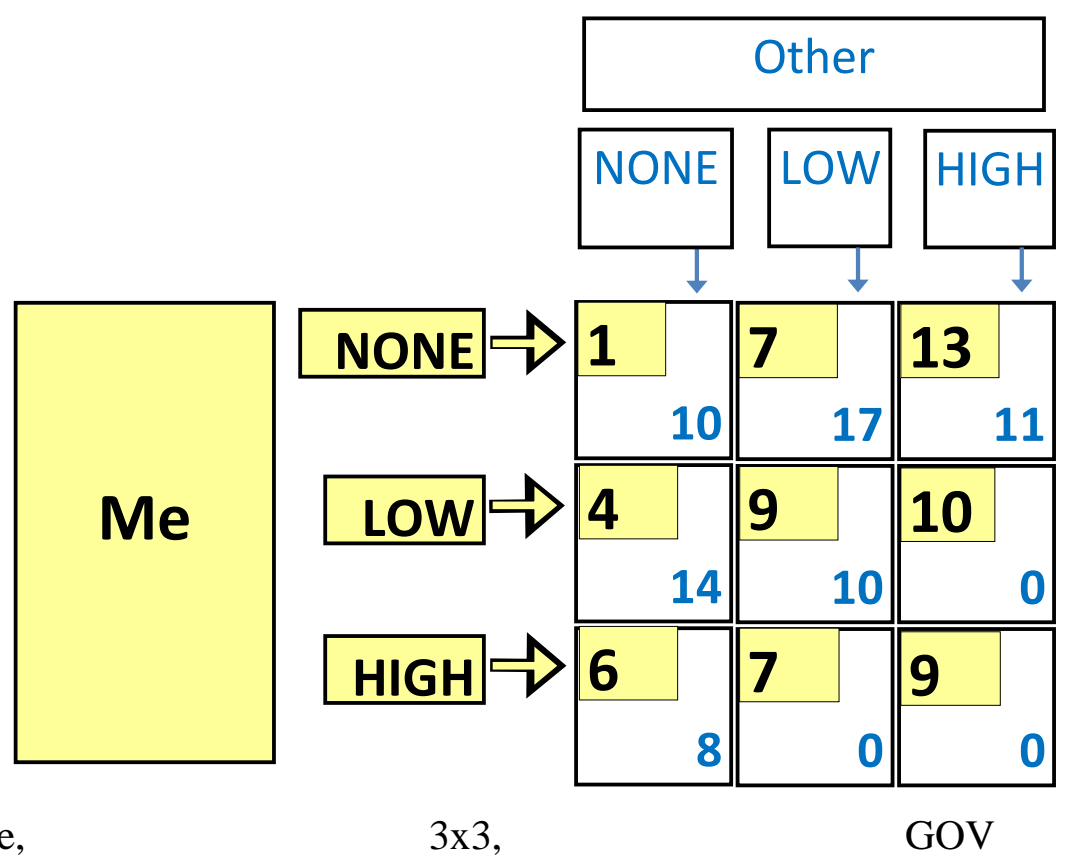

Base,

$3 \times 3$,

GOV 
[Alt, 3x3, SRO

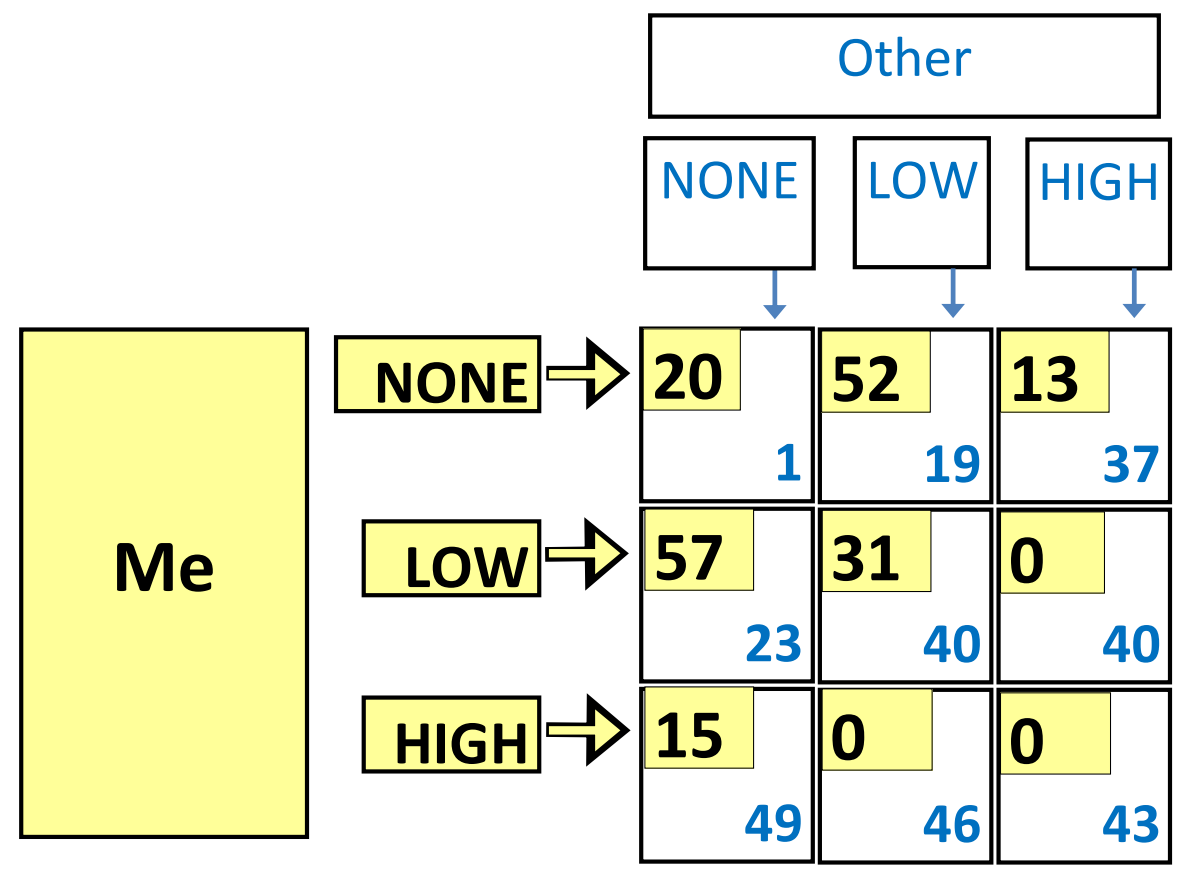

Alt, 3x3, SRO]

[Alt, 3x3, GOV

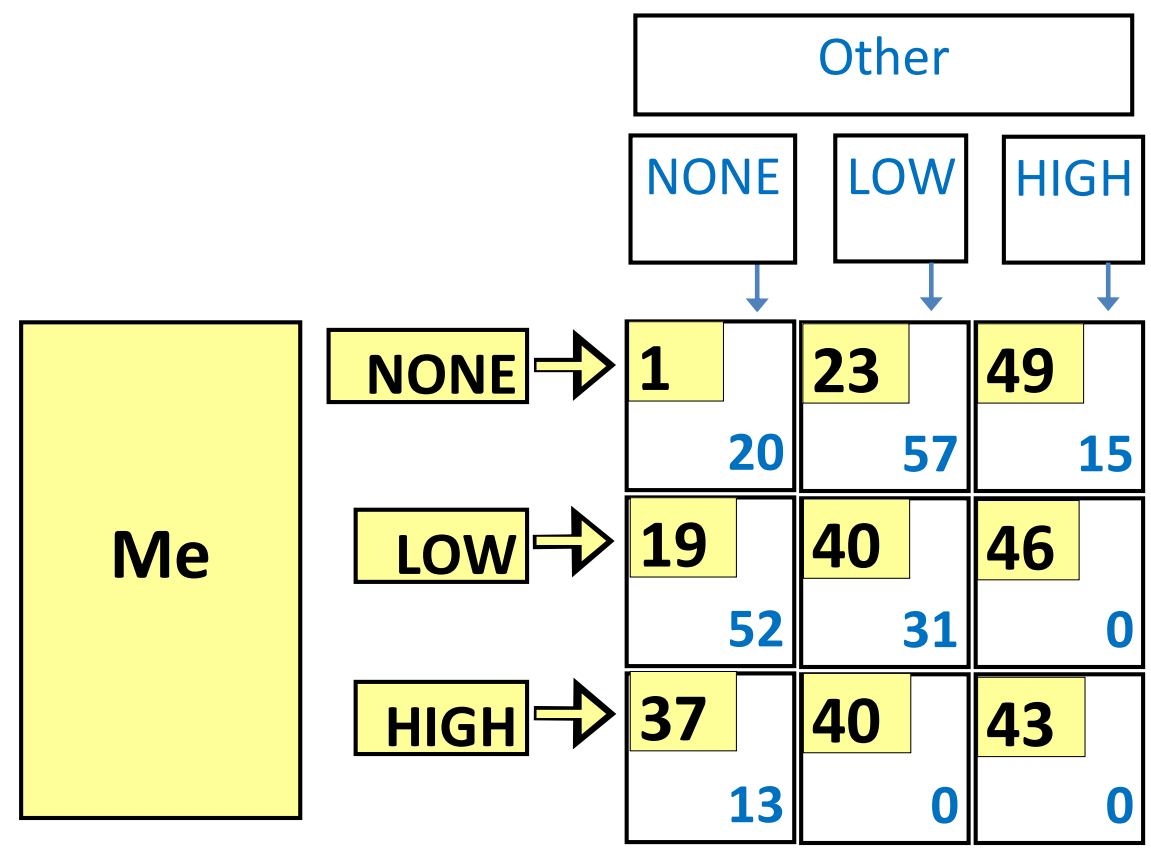

Alt, 3x3, GOV] 
[Base, 6x6, SRO

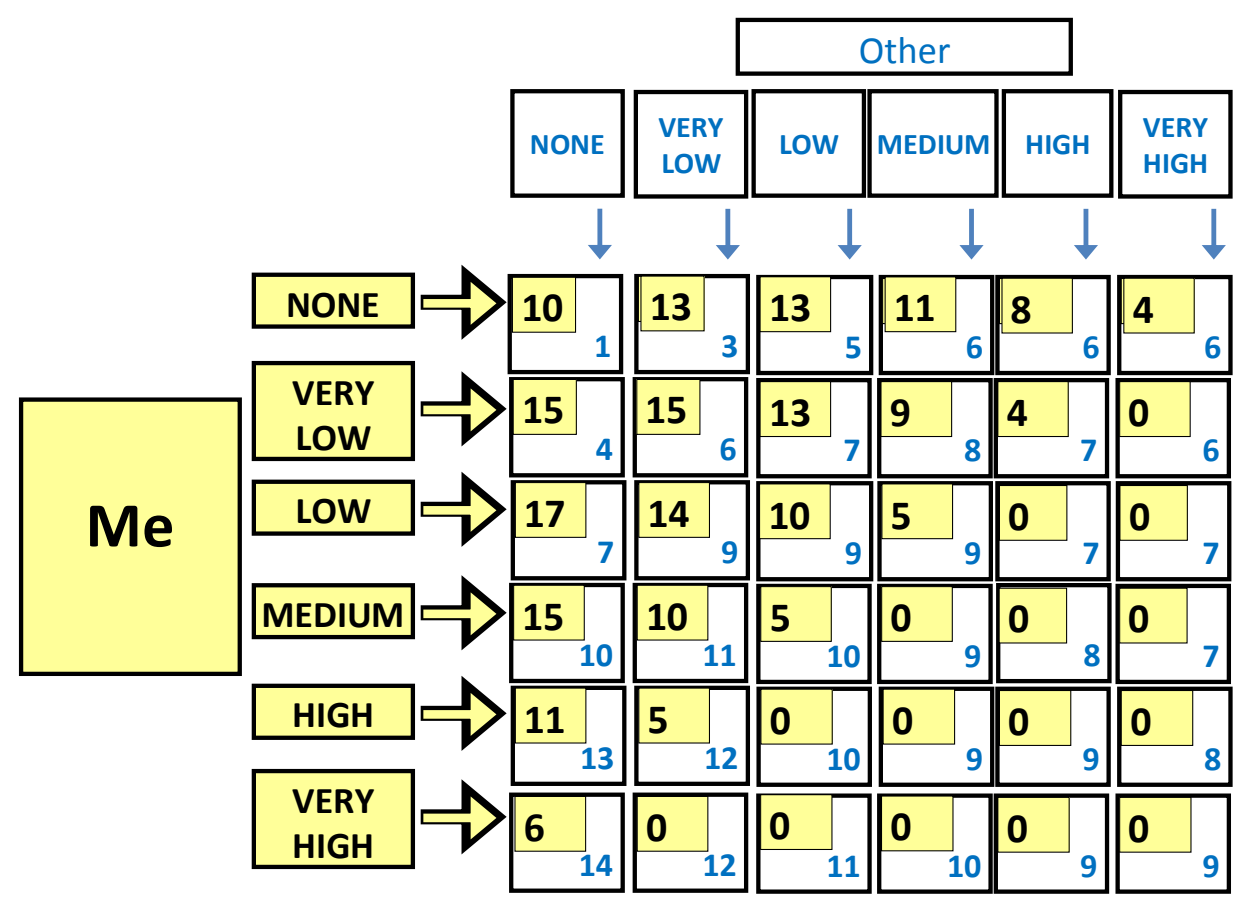

Base, 6x6, SRO]

[Base, 6x6, GOV

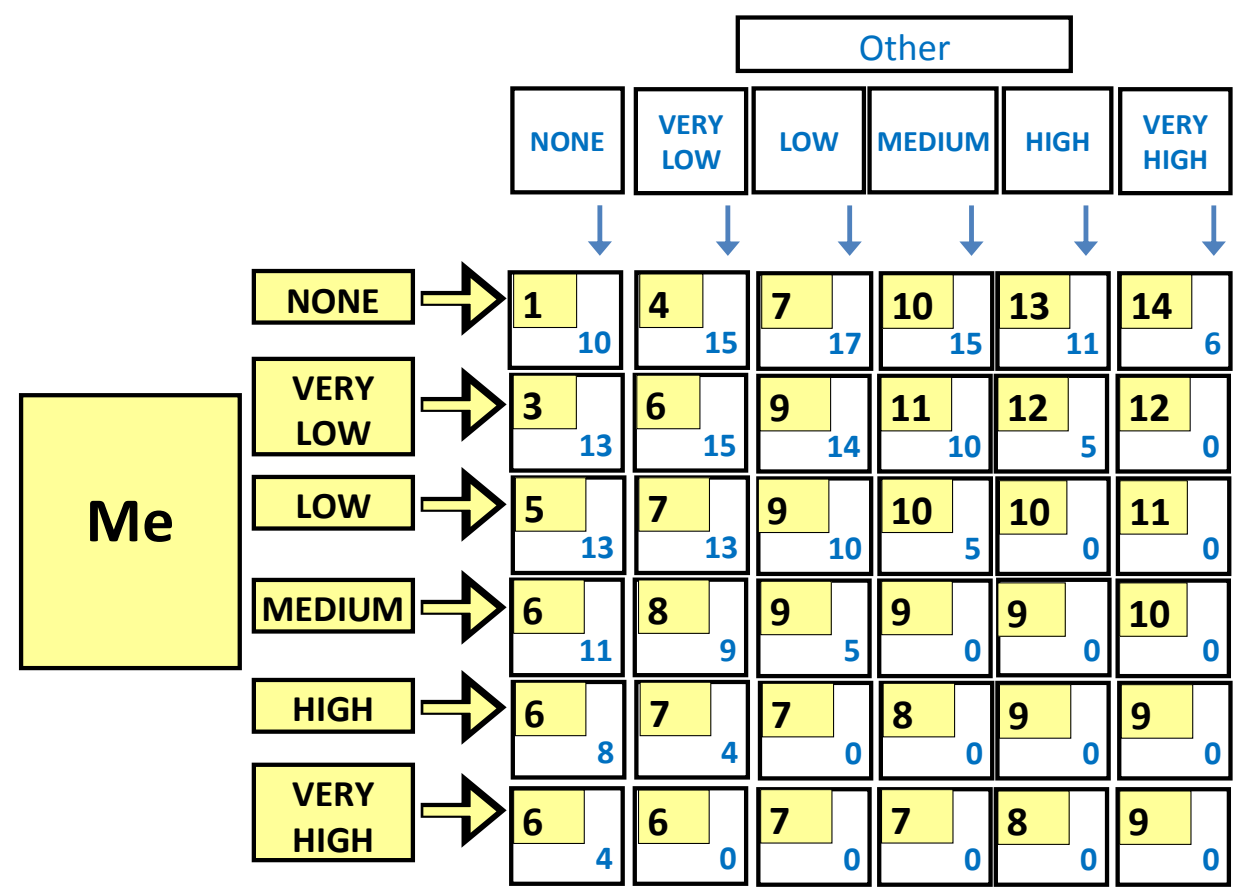

Base, 6x6, GOV]

[Base, Ext, SRO 


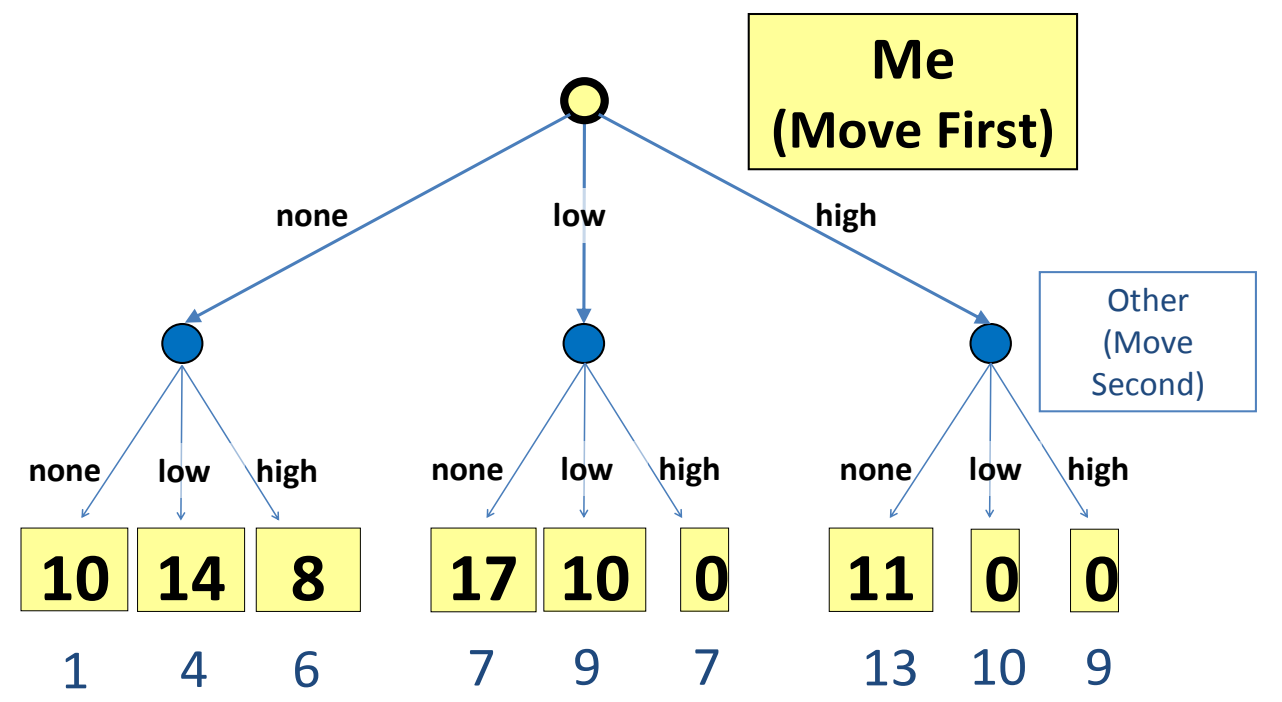

Base, Ext, SRO]

[Base, Ext, GOV

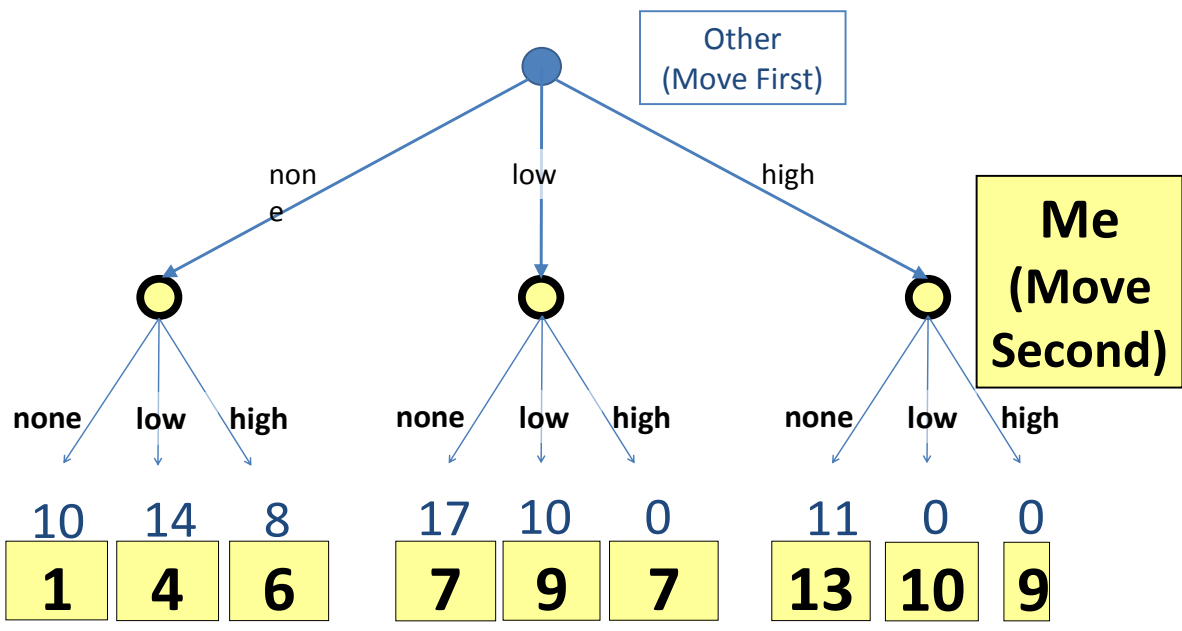

Base, Ext, GOV] 


\section{References}

Charness, G. and Sutter, M. (2012). Groups Make Better Self-Interested Decisions, Journal of Economic Perspectives, 26, 157 - 176.

Cooper, D. J. and Kagel, J. H. (2005). Are Two Heads Better Than One? Team Versus Individual Play in Signaling Games, American Economic Review, 95, 477 - 509.

DeMarzo, P. M., Fishman, M. J., and Hagerty, K. M. (2005). Self-Regulation and Government Oversight, Review of Economic Studies, 72, 687 - 706.

Eckel, C. and Lutz, N. (2003). Introduction: What Role Can Experiments Play in Research on Regulation? Journal of Regulatory Economics 23(2), 103 - 107.

Gehrig, T. and Jost, P-J. (1995). Quacks, Lemons, and Self Regulation: A Welfare Analysis. Journal of Regulatory Economics 7, 309 - 325.

Hilary, G. and Lennox, C. (2005). The Credibility of Self-Regulation: Evidence from the Accounting Profession's Peer Review Program, Journal of Accounting and Economics, 40, $211-229$.

Hinloopen, J., Müller, W., and Normann, H. (2012). Output Commitment through Product Bundling: Experimental Evidence, Tinbergen Institute Discussion Paper No. $11-170 / 1$.

Holt, C. and Laury, S. K. (2002). Risk Aversion and Incentive Effects, The American Economic Review, 92, 1644 - 1655.

Huck, S., Müller, W., and Normann, H. (2001). Stackelberg Beats Cournot: On Collusion and Efficiency in Experimental Markets, Economic Journal, 111, 749 765.

Kleiner, M. M. (2006). Licensing Occupations: Ensuring Quality or Restricting Competition? (W. E. Upjohn Institute for Employment Research).

List, J. A. (2006). The Behavioralist Meets the Market: Measuring Social Preferences and Reputation Effects in Actual Transactions, Journal of Political Economy, 114, 1 -37 .

Maute, J. L. (2008). Bar Associations, Self-Regulation and Consumer Protection: Whither Thou Goest?, Journal of the Professional Lawyer, 53 - 85.

Nunez, J. (2001). A Model of Self-Regulation, Economics Letters, 74, 91 - 97. 
Nunez, J. (2007). Can Self-Regulation work? A Story of Corruption, Impunity and Cover-up, Journal of Regulatory Economics, 31, 209 - 233.

Ortmann, A. and Mysliveček, J. (2010). Certification and Self-Regulation of NonProfits, and the Institutional Choice Between Them, in Seaman, B. and Young, D. (eds) Handbook of Nonprofit Economics and Management (Cheltanham: Edward Elgar Publishing Company).

Ortmann, A. and Svitkova, K. (2010). Do Self-Regulation Clubs Work? Some Evidence from Europe and Some Caveats From Economic Theory, in Gugerty, M. K. and Prakash, A. (eds) Voluntary Regulation of NGOs and Non-Profits: An Accountability Club Framework (Cambridge: Cambridge University Press).

Rees, J. V. (1997). The Development of Communitarian Regulation in the Chemical Industry, Law Policy, 17, 477 - 528.

Rydval, O. and Ortmann, A. (2004). How Financial Incentives and Cognitive Abilities Affect Task Performance in Laboratory Settings: An Illustration, Economics Letters, $85,315-320$.

Shaked, A. and Sutton, J. (1981). The Self-Regulating Profession, The Review of Economic Studies, 48, 217 - 234.

Sidel, M. (2005). The Guardians Guarding Themselves: A Comparative Perspective on Nonprofit Self-Regulation, Kent Law Review, 80, 803 - 835.

Studdert, D. M., Mello, M. M., and Brennan, T. A. (2004). Financial Conflicts of Interest in Physicians' Relationship with the Pharmaceutical Industry: SelfRegulation in the Shadow of Federal Prosecution, New England Journal of Medicine, 351, 1891 - 1900.

Van Koten (mimeo). Self-regulation under the shadow of governmental oversight: blossom or perish? 


\section{Working Paper Series}

ISSN 1211-3298

Registration No. (Ministry of Culture): E 19443

Individual researchers, as well as the on-line and printed versions of the CERGE-EI Working Papers (including their dissemination) were supported from institutional support RVO 67985998 from Economics Institute of the ASCR, v. v. i.

Specific research support and/or other grants the researchers/publications benefited from are acknowledged at the beginning of the Paper.

(c) Silvester Van Koten and Andreas Ortmann, 2014

All rights reserved. No part of this publication may be reproduced, stored in a retrieval system or transmitted in any form or by any means, electronic, mechanical or photocopying, recording, or otherwise without the prior permission of the publisher.

Published by

Charles University in Prague, Center for Economic Research and Graduate Education (CERGE) and

Economics Institute of the ASCR, v. v. i. (EI)

CERGE-El, Politických vězňů 7, 11121 Prague 1, tel.: +420 224005 153, Czech Republic.

Printed by CERGE-EI, Prague

Subscription: CERGE-EI homepage: http://www.cerge-ei.cz

Phone: + 420224005153

Email: office@cerge-ei.cz

Web: http://www.cerge-ei.cz

Editor: Marek Kapička

The paper is available online at http://www.cerge-ei.cz/publications/working_papers/.

ISBN 978-80-7343-324-6 (Univerzita Karlova. Centrum pro ekonomický výzkum a doktorské studium)

ISBN 978-80-7344-316-0 (Akademie věd České republiky. Národohospodářský ústav) 
CERGE-EI

P.O.BOX 882

Politických vězňů 7

11121 Praha 1

Czech Republic http://www.cerge-ei.cz 